\title{
A New Model to Downscale Urban and Rural Surface and Air Temperatures Evaluated in Shanghai, China
}

\author{
DONGWEI LIU \\ Shanghai Institute of Meteorological Science, Shanghai Meteorological Service, Shanghai, China \\ C. S. B. GRIMMOND \\ Department of Meteorology, University of Reading, Reading, United Kingdom
}

JIANGUO TAN

\begin{abstract}
Shanghai Climate Center, Shanghai Meteorological Service, and Key Open Laboratory of Cities' Mitigation and Adaptation to Climate Change in Shanghai, China Meteorological Administration, and Shanghai Key Laboratory of Meteorology and Health, Shanghai Meteorological Service, Shanghai, China
\end{abstract}

\author{
Xiangyu Ao, Jie Peng, And Linli Cui
}

Shanghai Institute of Meteorological Science, and Shanghai Key Laboratory of Meteorology and Health, Shanghai Meteorological Service, Shanghai, China

BingXin Ma, Yan Hu, AND MingBin Du

Shanghai Institute of Meteorological Science, Shanghai Meteorological Service, Shanghai, China

(Manuscript received 14 September 2017, in final form 22 July 2018)

\begin{abstract}
A simple model, the Surface Temperature and Near-Surface Air Temperature (at $2 \mathrm{~m}$ ) Model (TsT2m), is developed to downscale numerical model output (such as from ECMWF) to obtain higher-temporal- and higherspatial-resolution surface and near-surface air temperature. It is evaluated in Shanghai, China. Surface temperature $\left(T_{s}\right)$ and near-surface air temperature $\left(T_{a}\right)$ submodels account for variations in land cover and their different thermal properties, resulting in spatial variations of surface and air temperature. The net all-wave radiation parameterization (NARP) scheme is used to compute net wave radiation for the surface temperature submodel, the objective hysteresis model $(\mathrm{OHM})$ is used to calculate the net storage heat fluxes, and the surface temperature is obtained by the force-restore method. The near-surface air temperature submodel considers the horizontal and vertical energy changes for a column of well-mixed air above the surface. Modeled surface temperatures reproduce the general pattern of MODIS images well, while providing more detailed patterns of the surface urban heat island. However, the simulated surface temperatures capture the warmer urban land cover and are $10.3^{\circ} \mathrm{C}$ warmer on average than those derived from the coarser MODIS data. For other land-cover types, values are more similar. Downscaled, higher-temporal- and higher-spatial-resolution air temperatures are compared to observations at 110 automatic weather stations across Shanghai. After downscaling with TsT2m, the average forecast accuracy of near-surface air temperature is improved by about $20 \%$. The scheme developed has considerable potential for prediction and mitigation of urban climate conditions, particularly for weather and climate services related to heat stress.
\end{abstract}

\section{Introduction}

Rapid urbanization globally has resulted in land-use and land-cover changes that have significantly affected

Corresponding author: Prof. Jianguo Tan, jianguot@21cn.com, tanjg@smb.gov.cn climate (Jin et al. 2011; Bechtel et al. 2012). One of the most well-known urban climatic effects is the enhanced surface and air temperatures in cities, the urban heat island (UHI; Oke 1973; Kim and Baik 2005; Yow 2007). Many aspects of urban life are impacted (Oke 1995; Stone and Rodgers 2001; Weng et al. 2004) including human health and well-being (Basu and Samet 2002), 
the operations of city infrastructure (O'Malley et al. 2014), and ecological (Raich and Schlesinger 1992; Trumbore et al. 1996) and hydrological (Grimm et al. 2008; Kalma et al. 2008) processes. Thus, the ability to simulate high-resolution surface or near-ground air temperatures in cities is of considerable interest for a wide range of applications.

Satellite remote sensing has many advantages for monitoring land surface temperatures. Past studies have shown that the UHI derived from remote sensing responds to spatial patterns of surface characteristics (Roth et al. 1989; Gallo et al. 1993; Nichol et al. 2009). However, for many applications the value of remote sensing is limited by cloud cover, low temporal resolution of imagery, and/or coarse spatial resolution, although downscaling methods exist to address the latter (Xu et al. 2008; Bechtel et al. 2012; Bonafoni 2016).

Numerical simulations provide an effective way to forecast surface and/or air temperatures. Models are available for different surface types, including crops (Luo et al. 1992; Mihailović and Eitzinger 2007) and roads (Shao and Lister 1996; Diefenderfer et al. 2006). Methods underpinning these include obtaining the ground surface temperature by solving the surface energy balance equation (e.g., Best 1998; Herb et al. 2008); statistical downscaling from coarser-resolution models assuming stationary empirical relations (Winkler et al. 1997); multiobjective genetic-programming-based method to downscaling near-surface temperature by high-resolution information on land surface properties (Zerenner et al. 2016); and dynamic downscaling using a mesoscale model, for example, the Weather Research and Forecasting (WRF) Model (Pan et al. 2012).

An extensive comparison of 33 urban land surface models (ULSM) conducted as part of an international urban energy balance models comparison project (Grimmond et al. 2010) found, in general, simpler models perform just as well as more complex models (Grimmond et al. 2011; Best and Grimmond 2015). This finding is attributed, in part, to the ability of individual models to use the available input parameters and the difficulties of determining some of the parameters employed in more complex schemes. Moreover, complex models may require more computing resources (e.g., time, power). However, advances are being made with simple, practical models for cities (e.g., Wang et al. 2017; Lindberg et al. 2018).

This paper presents a novel simple model [the Surface Temperature and Near-Surface Air Temperature (at $2 \mathrm{~m}$ ) Model (TsT2m)] for simulating high-spatialresolution surface and near-surface air temperatures (2-m height). The model accounts for differences in surface cover proportion within a city (i.e., beyond coarse urban and rural differences) while using standard meteorological station data and easily obtained parameters. Critically, it runs rapidly and so permits operational high-resolution air temperature forecasts that allow heat- and cold-related urban climate and weather services to be provided. It considers both the surface energy budget and the effects of horizontal airflow. TsT2 $\mathrm{m}$ is evaluated in Shanghai, a city with greater than 23 million inhabitants, more than 2.6 million automobiles, and more than 32000 tall buildings ( $>30 \mathrm{~m}$ tall) in the year 2010 (Tan et al. 2015). Results are compared with 10-day weather forecast datasets derived from ECMWF model output (Molteni et al. 1996) and automatic weather station (AWS) observations distributed across the city of Shanghai.

\section{TsT2m description}

\section{a. Model structure}

TsT2 $\mathrm{m}$ uses the surface energy balance to calculate surface temperature $T_{s}$ (Ts submodel) and a dynamic energy balance of a column of air to diagnose the near-surface air temperature at $2-\mathrm{m}$ height $T_{a}(\mathrm{~T} 2 \mathrm{~m}$ submodel).

\section{b. Surface temperature model (Ts submodel)}

For the surface temperature model, the surface energy balance for each land-cover type is described as (Oke 1988)

$$
Q^{*}+Q_{F}=Q_{H}+Q_{E}+\Delta Q_{s},
$$

where $Q^{*}$ is net all-wave radiation, and $Q_{F}, Q_{H}, Q_{E}$, and $\Delta Q_{S}$ are the anthropogenic heat, turbulent sensible heat, turbulent latent heat, and net storage heat fluxes, respectively. The net all-wave radiation parameterization (NARP) scheme (Offerle et al. 2003; Loridan et al. 2011) is used to calculate $Q^{*}$. NARP requires routine meteorological data (near-surface air temperature $T_{a}$, humidity, pressure, cloud cover, wind, etc.) and surface physical properties (surface albedo $\alpha$, broadband surface emissivity $\varepsilon_{s}$, etc.):

$$
\begin{aligned}
& Q^{*}=(1-\alpha) K_{\downarrow}+L_{\downarrow}-L_{\uparrow} \quad \text { and } \\
& L_{\downarrow}=\varepsilon_{\text {sky }} \sigma T_{a}^{4},
\end{aligned}
$$

where $\varepsilon_{\text {sky }}$ is broadband atmospheric emissivity, and $\sigma$ is the Stefan-Boltzmann constant (Offerle et al. 2003):

$$
L_{\uparrow}=\varepsilon_{s} \sigma T_{a}^{4}+0.08 K_{\downarrow}(1-\alpha)+\left(1-\varepsilon_{s}\right) L_{\downarrow} .
$$

The value of $K_{\downarrow}$ depends on solar geometry and the solar constant $R_{0}$ : 


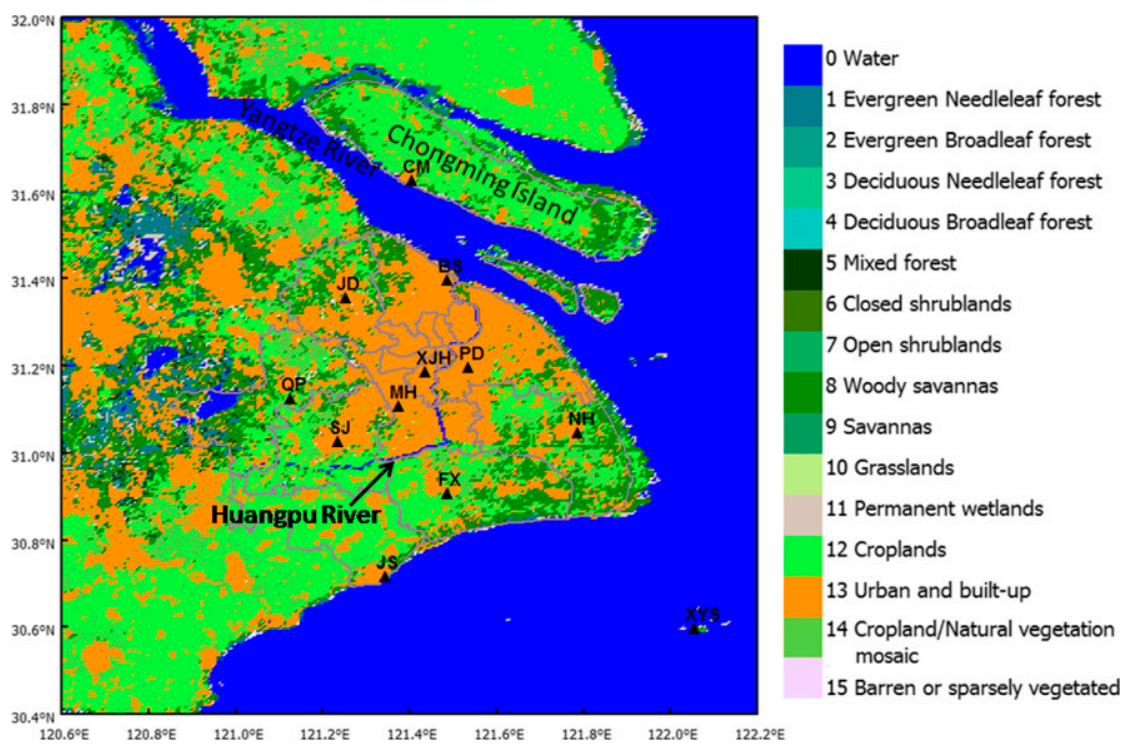

FIG. 1. Land use (IGBP classes: numbers and color) and location of AWSs in the Shanghai region (province and constituent districts: gray lines) based on 2010 MODIS imagery (see text). The AWS national station codes are as follows: BS: Baoshan; CM: Chongming; FX: Fengxian; JD: Jiading; JS: Jinshan; MH: Minghang; SJ: Songjiang; PD: Pudong; XJH: Xujiahui; and QP: Qingpu. The eddy covariance (EC) tower is also at XJH, about $50 \mathrm{~m}$ from the AWS site. Simulated area is the same extent as this map $\left(30.5^{\circ}-32.0^{\circ} \mathrm{N}, 120.7^{\circ}-122.2^{\circ} \mathrm{E}\right)$.

$$
K_{\downarrow}=T_{r} R_{0} \cos (h),
$$

where $h$ is the solar zenith angle. The atmospheric transmittance $T_{r}$ is calculated as follows (Shao and Lister 1996):

$$
T_{r}=f_{\mathrm{e}_{-} s} t_{R} t_{\mathrm{pg}} t_{w} t_{a} t_{c},
$$

where $f_{\mathrm{e}_{\mathrm{s}} \mathrm{s}}$ is a factor to account for deviation in mean Earth-sun distance based on day of year $D$ :

$$
f_{\mathrm{e} \_\mathrm{s}}=1+0.034 \cos \left[\frac{2 \pi(D-1)}{365}\right] .
$$

The absorption by water vapor $t_{w}$ is calculated as follows (McDonald 1960):

$$
t_{w}=1-0.077(\mu m)^{0.3},
$$

from the precipitable water $\mu$ that requires an empirical constant $G$ dependent upon time of year and latitude and dewpoint temperature $T_{\text {dew }}$ (Smith 1966):

$$
\mu=\exp \left[1.3709-\ln (G+1)+0.07074 T_{\text {dew }}\right],
$$

and optical mass $m$ (Shao and Lister 1996):

$$
m=35\left[1224 \cos ^{2}(h)+1\right]^{1 / 2} .
$$

The absorption and scattering of aerosols $t_{a}$ is calculated as follows (Meyers and Dale 1983):

$$
t_{a}=0.935^{m} .
$$

The Rayleigh scattering and absorption by the permanent gases $t_{R} t_{\mathrm{pg}}$ additionally requires pressure $p$ (Atwater and Brown 1974):

$$
t_{R} t_{\mathrm{pg}}=1.021-0.084\left[m\left(949 p \times 10^{-6}+0.051\right)\right]^{1 / 2} .
$$

Cloud transmittance $t_{c}$ uses cloud fraction $\left(\mathrm{CC}_{i}, 0-1\right)$ and is the cloud transmittance by cloud level $\left(c_{i}\right.$, where $i=$ low, medium, and high cloud) following Atwater and Ball (1981):

$$
t_{c}=\prod_{i=1}^{3}\left[1-\mathrm{CC}_{i}\left(1-c_{i}\right)\right]
$$

If only total cloud-cover fraction $\left(\mathrm{CC}_{1}\right)$ and/or lower/ middle $\left(\mathrm{CC}_{2}\right)$ cloud cover are available, this becomes

$$
t_{c}=\left[1-\left(\mathrm{CC}_{1}-\mathrm{CC}_{2}\right)\left(1-c_{1}\right)\right]\left[1-\mathrm{CC}_{2}\left(1-c_{2}\right)\right],
$$

where $c_{1}$ is cloud transmittance without low cloud, and $c_{2}$ is cloud transmittance without high cloud. In this study, to evaluate $c_{1}$ and $c_{2}$, a sensitivity test (at 0.2 steps in each parameter, from 0.0 to 1.0) is performed using 
observations of cloud cover $\left(\mathrm{CC}_{1}, \mathrm{CC}_{2}\right)$ and $K_{\downarrow}$ at the Xujiahui (XJH) site in Shanghai (Fig. 1). The value of $K_{\downarrow}$ is calculated [Eqs. (4)-(14)] when $K_{\downarrow}>0 \mathrm{~W} \mathrm{~m}^{-2}$ and cloud observations are available [December 2012August 2013 at 0800 and 1400 local time (LT) (UTC +8 h), 712 thirty-minute data points]. The goodness-of-fit metrics used are the root-mean-square error (RMSE), standard deviation, and correlation coefficient. The best estimate of $K_{\downarrow}$ occurred when $c_{1}=0.4$ and $c_{2}=0.8$ (Fig. 2, point A). These values are used in the remainder of this study.

The total input of energy in an urban environment $\left(Q^{F *}=Q^{*}+Q_{F}\right)$ requires the anthropogenic heat flux $Q_{F}$ to be determined. Here, the Large-Scale Urban Consumption of Energy Model (LUCY) model (Allen et al. 2011; Gabey et al. 2018) with three sources of $Q_{F}$ (traffic, building, and human metabolic emissions) is used. The traffic data are based on International Road Federation (IFR) World Road Statistics 2005, with the average traffic speed set to $48 \mathrm{~km} \mathrm{~h}^{-1}$. The population data are from the 2000 Global Rural Urban Mapping Project (GRUMP). For the average daily air temperature, the XJH station (September 2012-August 2013) data are used.

We obtain $\Delta Q_{S}$ from the objective hysteresis model (OHM; Grimmond et al. 1991):

$$
\begin{aligned}
\Delta Q_{s}= & \sum_{i=1}^{n}\left(f_{i} a_{1 i}\right) Q^{F *}+\sum_{i=1}^{n}\left(f_{i} a_{2 i}\right)\left(\frac{\partial Q^{F *}}{\partial t}\right) \\
& +\sum_{i=1}^{n}\left(f_{i} a_{3 i}\right)
\end{aligned}
$$

where $f_{i}$ is the proportion of surface type $i ; a_{1 i}, a_{2 i}$, and $a_{3 i}$ are the OHM coefficients (Table 1 ); $n$ is the number of surface types; and $t$ is the time. This is a robust, welltested method to calculate the heat flux of stored energy in urban areas (e.g., Arnfield and Grimmond 1998; Taha 1999; Roth et al. 1989; Grimmond and Oke 1999; Roberts et al. 2006).

Bhumralkar (1975) and Blackadar (1976) developed a two-layer force-restore scheme to describe surface temperature variations. This is applied widely in land-air schemes (e.g., Xue et al. 1991; Mihailović 1991, 1996). Using $\Delta Q_{S}$, we calculate surface temperature $T_{S}$ by the forcerestore method over different urban land-cover types (e.g., building, pavement, vegetation, trees, water, barren):

$$
C_{0} \frac{\partial T_{s}}{\partial t}=\Delta Q_{s}-C\left(\frac{K_{T} \omega}{2}\right)^{1 / 2}\left(T_{s}-T_{d}\right)
$$

where $T_{d}$ is a deep $(z \sim \infty)$ soil temperature at the substrate heat reservoir ( $\mathrm{Hu}$ and Islam 1995). The value of $T_{d}$ is usually set as a constant, but for a limited period

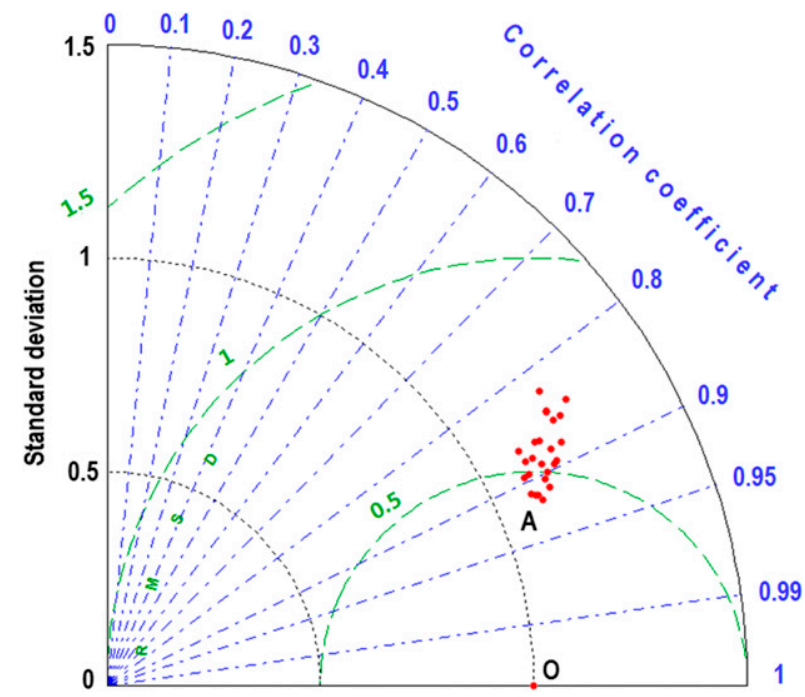

FIG. 2. Normalized Taylor (2001) diagram for simulated incoming shortwave radiation assessed with observations from the XJH flux tower (Ao et al. 2016a) with changing combinations of transmission coefficients $c_{1}$ and $c_{2}$ (0.2 increment steps) for the period December 2012-August 2013 (30 min, at 0800 and 1400 LT, 712 samples). The ideal model performance is point $\mathrm{O}$ on the $x$ axis. Points (red) are located based on the normalized standard deviation, correlation coefficient, and normalized RMSE. The best fit (point A) occurs with $c_{1}=0.4$ and $c_{2}=0.8$.

such as 1 day, the deep $(z \sim \infty)$ soil temperature is not modified and a shallower slowly varying daily temperature is appropriate. Here, observed soil temperature at a depth of $0.2 \mathrm{~m}$ is used. Also, $C$ is the volumetric heat capacity, $K_{T}$ is the thermal conductivity, and $C_{0}$ is the heat capacity per unit area, determined from

$$
C_{0}=0.95 C\left(K_{T} / 2 w\right)^{0.5},
$$

where $\omega=2 \pi / \tau$ and $\tau$ is 1 day $(24 \times 3600 \mathrm{~s})$.

\section{c. Near-surface air temperature model (T2m submodel)}

Given a column of well-mixed air of height $Z_{i}$ above a surface, the temperature change depends on the internal energy change $\Delta Q_{a}$, including the horizontal energy change $\Delta Q_{a, h}$, and the vertical energy change $\Delta Q_{\mathrm{L}_{-} \mathrm{V}}$ :

$$
\Delta Q_{a}=\Delta Q_{a, h}+\Delta Q_{\mathrm{L}_{-} \mathrm{V}} .
$$

The vertical energy change of the column of air $\Delta Q_{\mathrm{L}_{-} \mathrm{V}}$ is set to equal the changes caused by surface longwave radiation heat $\Delta L_{\uparrow 0}$ and longwave radiation change at the top of the air column $\Delta L_{\uparrow Z_{i}}$ :

$$
\Delta Q_{\mathrm{L}_{-} \mathrm{V}}=\left(\Delta L_{\uparrow 0}+\Delta L_{\uparrow Z_{i}}\right) A \Delta t
$$


TABLE 1. Parameters required for OHM and values used for each land-use class (IGBP codes; Fig. 2).

\begin{tabular}{|c|c|c|c|c|c|c|c|c|}
\hline \multirow[b]{2}{*}{$\begin{array}{l}\text { IGBP } \\
\text { type }\end{array}$} & \multirow[b]{2}{*}{ Type } & \multicolumn{3}{|c|}{ OHM } & \multicolumn{2}{|c|}{ Radiation } & \multicolumn{2}{|c|}{ Conduction } \\
\hline & & $a_{1}$ & $a_{2}(\mathrm{~s})$ & $a_{3}\left(\mathrm{~W} \mathrm{~m}^{-2}\right)$ & Albedo & Emissivity & $\begin{array}{l}\text { Heat capacity } \\
\left(\mathrm{MJ} \mathrm{m}^{-3} \mathrm{~K}^{-1}\right)\end{array}$ & $\begin{array}{l}\text { Thermal conductivity } \\
\qquad\left(\mathrm{W} \mathrm{m}{ }^{-1} \mathrm{~K}^{-1}\right)\end{array}$ \\
\hline 0 & Water bodies (WAT) & 0.50 & 0.21 & $-39.1^{\mathrm{a}}$ & $0.19^{\mathrm{g}}$ & $0.995^{\mathrm{i}}$ & $4.20^{\mathrm{j}}$ & 0.70 \\
\hline $10,12,14$ & Short vegetation (VEG) & 0.32 & 0.54 & $-27.4^{\mathrm{b}}$ & $0.19^{\mathrm{g}}$ & $0.93^{\mathrm{i}}$ & $2.50^{\mathrm{j}}$ & 0.40 \\
\hline $1-9$ & Trees and shrub (TRE) & 0.11 & 0.11 & $-12.3^{\mathrm{c}}$ & $0.25^{\mathrm{g}}$ & $0.97^{\mathrm{i}}$ & $2.50^{\mathrm{j}}$ & 0.40 \\
\hline 13 & Pavement (URB) & 0.72 & 0.19 & $-36.6^{\mathrm{d}}$ & $0.08^{\mathrm{h}}$ & $0.94^{\mathrm{h}}$ & $2.00^{\mathrm{j}}$ & 1.50 \\
\hline 13 & Building (URB) & 0.24 & 0.43 & $-16.7^{\mathrm{e}}$ & $0.14^{\mathrm{k}}$ & $0.90^{\mathrm{h}}$ & $2.00^{\mathrm{j}}$ & 1.00 \\
\hline 11,16 & Barren (BRN) & 0.38 & 0.56 & $-27.3^{f}$ & $0.12^{\mathrm{g}}$ & $0.953^{\mathrm{i}}$ & $2.40^{\mathrm{j}}$ & 0.70 \\
\hline
\end{tabular}

${ }^{\text {a }}$ South et al. (1998).

${ }^{\mathrm{b}}$ Doll et al. (1985).

${ }^{\mathrm{c}}$ McCaughey (1985).

d Average of impervious (Doll et al. 1985; Asaeda and Ca 1993; Narita et al. 1984; Anandakumar 1999).

e Average of roof (Meyn and Oke 2009; Järvi et al. 2014; Taesler 1980a,b; Yoshida et al. 1990).

${ }^{\mathrm{f}}$ Novak (1981).

${ }^{\mathrm{g}}$ Chen and Dudhia (2001).

${ }^{\mathrm{h}}$ Roberts et al. (2006).

${ }^{\mathrm{i}}$ Van De Griend and Owe (1993).

${ }^{\mathrm{j}}$ Herb et al. (2008).

${ }^{\mathrm{k}}$ Ao et al. (2016a).

where $A$ is the grid area and $\Delta t$ is the time span.

$$
\Delta L_{\uparrow 0}=\varepsilon_{s} \sigma T_{s, t}^{4}-\varepsilon_{s} \sigma T_{s, t-1}^{4},
$$

where $T_{s, t}$ and $T_{s, t-1}$ are the surface temperature at time $t$ and the preceding time $(t-1)$, respectively.

$$
\Delta L_{\uparrow Z_{i}}=\varepsilon_{\text {sky }} \sigma T_{Z_{i}, t}^{4}-\varepsilon_{\text {sky }} \sigma T_{Z_{i}, t-1}^{4}
$$

The air temperature high $(850 \mathrm{hPa})$ within the expected mixed layer $T_{Z_{i}}$, should reasonably represents the synopticscale changes and be impacted minimally by ground-based heat sources.

The energy brought by horizontal airflow $\Delta Q_{a, h}$ is a function of the total mass of a column of air in the grid $\left(m_{a}\right)$, the volumetric heat capacity of air $C_{a}$ and the change of air temperature $\left(\Delta T_{h}=T_{\text {in }}-T_{\text {out }}\right)$ caused by horizontal advection:

$$
\Delta Q_{a, h}=C_{a} m_{a} \Delta T_{h},
$$

where

$$
m_{a}=\rho A Z_{i},
$$

where $\rho$ is the density of air. From the internal energy change $\Delta Q_{a}$, the air temperature change in the column $\Delta T$ within time span $\Delta t$ is obtained:

$$
\begin{aligned}
\Delta T= & {\left[C_{a} m_{a} \Delta T_{h}+\left(\varepsilon_{\text {surf }} \sigma T_{s, t}^{4}-\varepsilon_{\text {surf }} \sigma T_{s, t-1}^{4}\right.\right.} \\
& \left.\left.+\varepsilon_{\text {sky }} \sigma T_{Z_{i}, t}^{4}-\varepsilon_{\text {sky }} \sigma T_{Z_{i}, t-1}^{4}\right) A \Delta t\right] / C_{a} m_{a},
\end{aligned}
$$

then

$$
\begin{aligned}
\Delta T= & \Delta T_{h}+\left(\varepsilon_{\text {surf }} \sigma T_{s, t}^{4}-\varepsilon_{\text {surf }} \sigma T_{s, t-1}^{4}\right. \\
& \left.+\varepsilon_{\text {sky }} \sigma T_{Z_{i}, t}^{4}-\varepsilon_{\text {sky }} \sigma T_{Z_{i}, t-1}^{4}\right) \Delta t / \rho Z_{i} .
\end{aligned}
$$

Precipitation modifies a number of important processes, including increases to the water vapor in the boundary layer, which affects the transmittance of the atmosphere air density and heat capacity; changes to the albedo of the surface (Ao et al. 2016a), which affects the shortwave radiation flux; increases to the surface latent heat flux, which changes the Bowen ratio (i.e., $Q_{H}$ and $Q_{E}$ partitioning) (Ao et al. 2016b); and soil moisture, which impacts the soil thermal conductivity and volumetric heat capacity. Although all of these processes impact surface temperature and air temperature, the model does not consider these hydrologic processes. Its performance on rainy days should be considered in this context. The influences of rainfall/ surface moisture on temperature are complex and need to be explored further in future model versions.

\section{Data and methods}

\section{a. Model parameter setting}

The detailed land-cover classification used by the surface temperature model is derived from the Moderate Resolution Imaging Spectroradiometer (MODIS) MOD12Q1 dataset (http://modis.gsfc.nasa.gov/data/ dataprod/mod12.php) with 500-m resolution, based on the International Geosphere-Biosphere Programme (IGBP) land-cover classification (Cohen et al. 2006). In the study area $\left(30.5^{\circ}-32.0^{\circ} \mathrm{N}, 120.7^{\circ}-122.2^{\circ} \mathrm{E}\right)$, the original 16 IGBP classes (Fig. 1) are reclassified into 


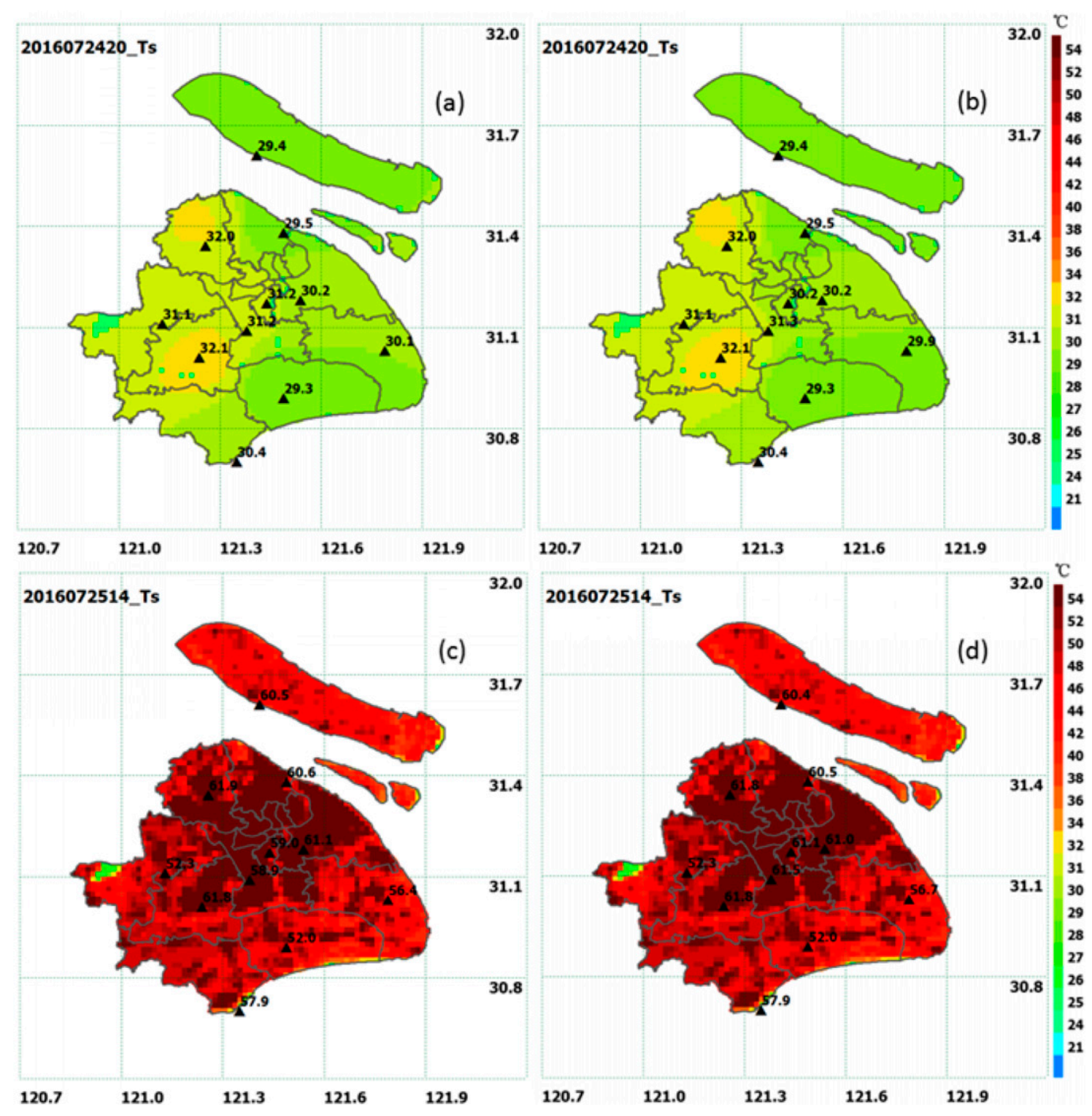

FIG. 3. Interpolated 2000 LT 24 Jul surface temperature (a) without XJH, (b) with XJH, and the resulting simulated surface temperature at $1400 \mathrm{LT}$ (c) without XJH and (d) with XJH. Gray lines delineate Shanghai and its districts.

six types for the OHM model (Table 1). The barren or sparsely vegetated category refers to land with no plants, building or water cover, but usually porous ground. Pavement is impermeable, such as concrete or asphalt road surfaces. As the 500-m MODIS data do not provide land-cover fractions (e.g., proportions of pavement, building, vegetation) detailed analyses of both residential and commercial areas in Shanghai use similar methods to Ao et al. (2016a) for XJH. From this the urban and built-up land-cover class is assumed to be have the following characteristics: paved areas $=58 \%$, buildings $=25 \%$, grass $=14 \%$, and trees $=3 \%$. To explore the model performance at the national AWS stations, the surface-cover metadata [based on Shanghai Institute of Surveying and Mapping data; see Table 4 in Tan et al. (2015)] within $1 \mathrm{~km}$ of each is analyzed.
The surface temperature submodel of TsT2m [Eqs. (1)(25)] is run with a spatial resolution of $0.015^{\circ}$ and 1 -h time step for the area of interest. It is initialized with a spatial dataset that includes surface temperature (bare soil), 2-m air temperature and humidity, 10-m wind direction and wind speed, and station pressure corrected to sea level. Data from the 10 AWS (Fig. 1) operated by the Shanghai Meteorological Service [see Tan et al. (2015) for more details about these stations] are interpolated by inverse distance weighting (IDW; Shepard 1968) to the model grid scale to provide model input. IDW is selected as it does not require other parameters (e.g., influence radius) and with the sites fixed in space the interpolation result is deterministic and results of adjacent grid points are continuous. Alternatives, such as nearest-neighbor (NN) interpolation may have 

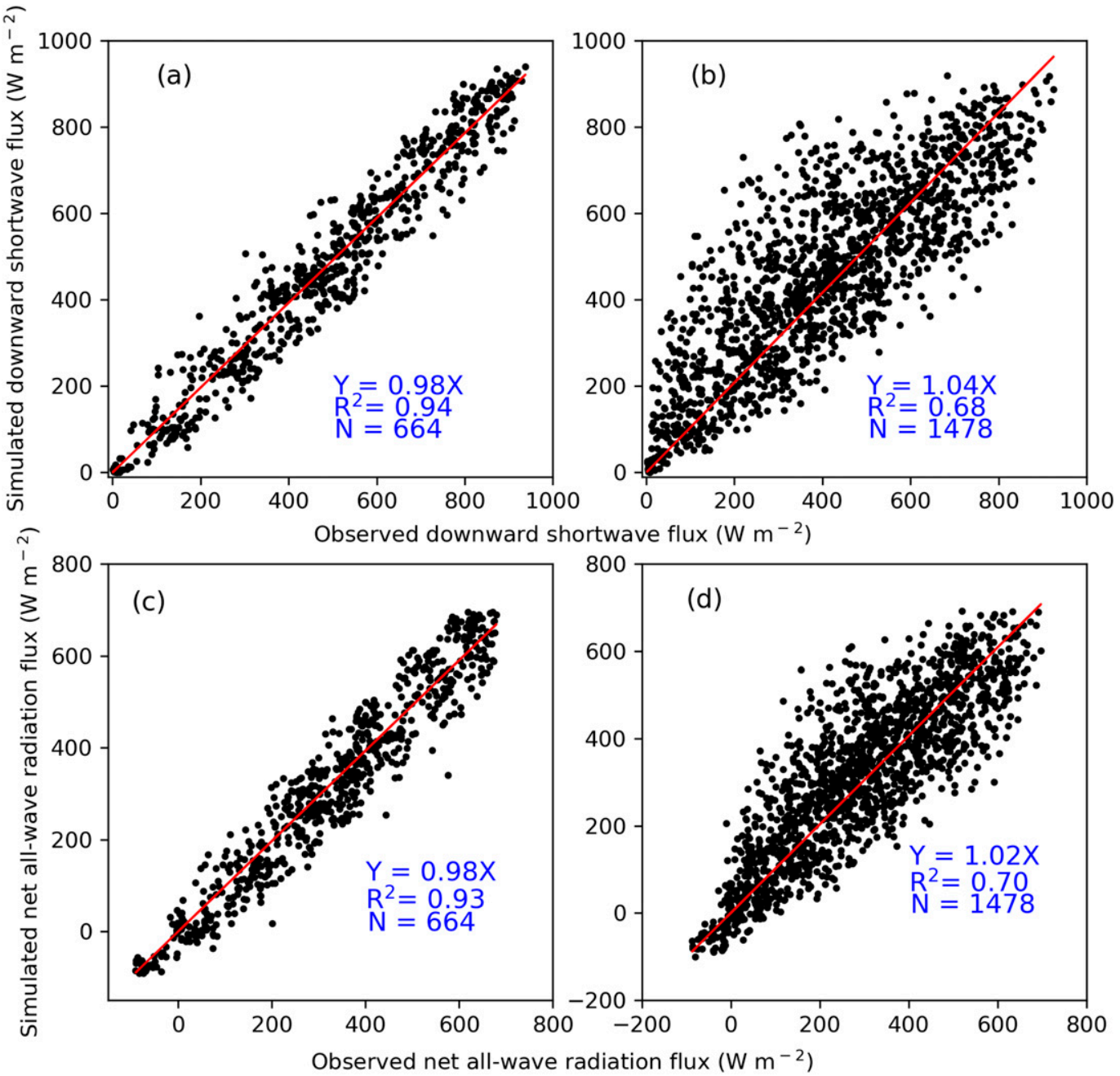

FIG. 4. Simulated hourly (a),(b) incoming shortwave and (c),(d) net all-wave radiation flux compared with observed data at the XJH tower for (a),(c) clear days $(N=664)$ and (b),(d) cloudy days $(N=1478)$ during December 2012-August 2013. Regression slope (forced through the origin) and coefficients of determination $R^{2}$ are given.

adjacent grid values that change abruptly. IDW is advantageous for routine interpolation. It has smaller errors than kriging or $\mathrm{NN}$ methods and is recommended for local-scale patterns of air temperature (e.g., Honjo et al. 2015; Li et al. 2017).

To assess the impact of the IDW interpolation, a clearsky case (24-25 July 2016; cloud cover around 10\%) is analyzed with and without the $\mathrm{XJH}$ station. The initial surface temperature of the $\mathrm{XJH}$ station area is $31.2^{\circ} \mathrm{C}\left(30.2^{\circ} \mathrm{C}\right)$ with (without) $\mathrm{XJH}$ and the corresponding simulated surface temperature at $1400 \mathrm{LT}$ are $59.0^{\circ}\left(61.1^{\circ}\right) \mathrm{C}$. The pattern of temperature distribution changes little (Fig. 3). For the investigation of the impact of the IDW interpolation method we have chosen to initiate the model with ECMWF run time after sunset at 2000 LT during which the temperature trends were not abruptly changing.

\section{b. Evaluation method}

The surface temperature submodel of TsT2m is evaluated for the period from 1 September 2012 to 31 August 2013. Simulated incoming shortwave and net all-wave radiation fluxes are compared against the XJH flux tower observations (Ao et al. 2016a) by season and weather type. Modeled surface temperatures are compared to twice daily (about 1100 and 1300 LT) MODIS land surface temperature products (MOD11C1), which have a resolution of $5 \mathrm{~km}$ (https://modis.gsfc.nasa. gov/data/dataprod/mod11.php).

The near-surface air temperature submodel of TsT2 $\mathrm{m}$ is initialized with interpolated surface and 

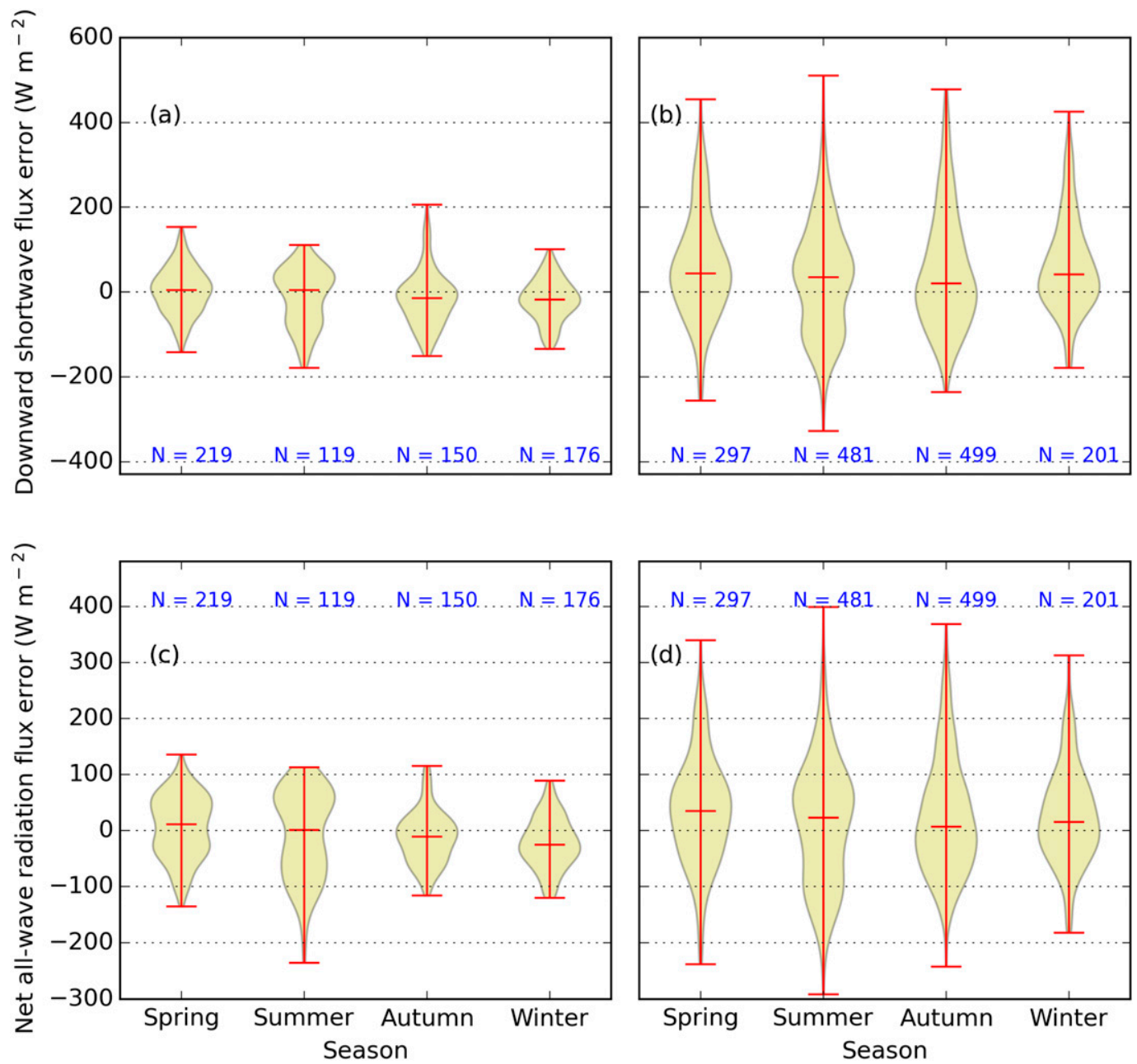

FIG. 5. Violin plot showing maximum, median, and minimum whiskers and the kernel density of simulated bias for (a),(b) incoming shortwave radiation flux $\left(K_{\downarrow \text { mod }}-K_{\downarrow \text { obs }}\right)$ and (c),(d) net all-wave radiation flux $\left(Q_{\text {mod }}^{*}-Q_{\text {obs }}^{*}\right)$ by seasons: (a),(c) clear (number of hours per season $N$ ) and (b),(d) cloudy days.

air temperatures from the 10 AWS observations. The ECMWF forecast 10-m wind direction and wind speed, humidity, air pressure, total and lower cloud cover (resolution $=0.125^{\circ}$ ), and 850 -hPa temperature (resolution $=0.25^{\circ}$ ) are used to force this submodel through interpolation. The new spatial resolution of $0.015^{\circ}$ for the model grid is obtained by bilinear interpolation. The 1-h temporal resolution (from $3 \mathrm{~h}$ ) is obtained by linear interpolation. Simulations are conducted from 1 May 2016 to 31 October 2016 using the next 24-h forecast (1200 UTC) with a 1-h time step. Simulated air temperatures are compared to the 3-h ECMWF forecast 2-m air temperature.

To evaluate the performance, coefficients of determination $R^{2}$, mean bias error (MBE), mean absolute error (MAE), and RMSE are used:

$$
\begin{aligned}
R^{2}= & \frac{\left[\sum_{i=1}^{N}\left(M_{i}-\bar{M}\right)\left(O_{i}-\bar{O}\right)\right]^{2}}{\sum_{i=1}^{N}\left(M_{i}-\bar{M}\right)^{2} \sum_{i=1}^{N}\left(O_{i}-\bar{O}\right)^{2}}, \\
\operatorname{MBE} & =\frac{1}{N} \sum_{i=1}^{N}\left(M_{i}-O_{i}\right), \\
\operatorname{MAE} & =\frac{1}{N} \sum_{i=1}^{N}\left(\left|M_{i}-O_{i}\right|\right), \quad \text { and } \\
\operatorname{RMSE} & =\sqrt{\frac{1}{N} \sum_{i=1}^{N}\left(M_{i}-O_{i}\right)^{2},}
\end{aligned}
$$

where $M_{i}$ indicates simulated and $O_{i}$ observed value for grid $i$ of the total $N$ grids or time steps; and $\bar{M}$ and $\bar{O}$ 

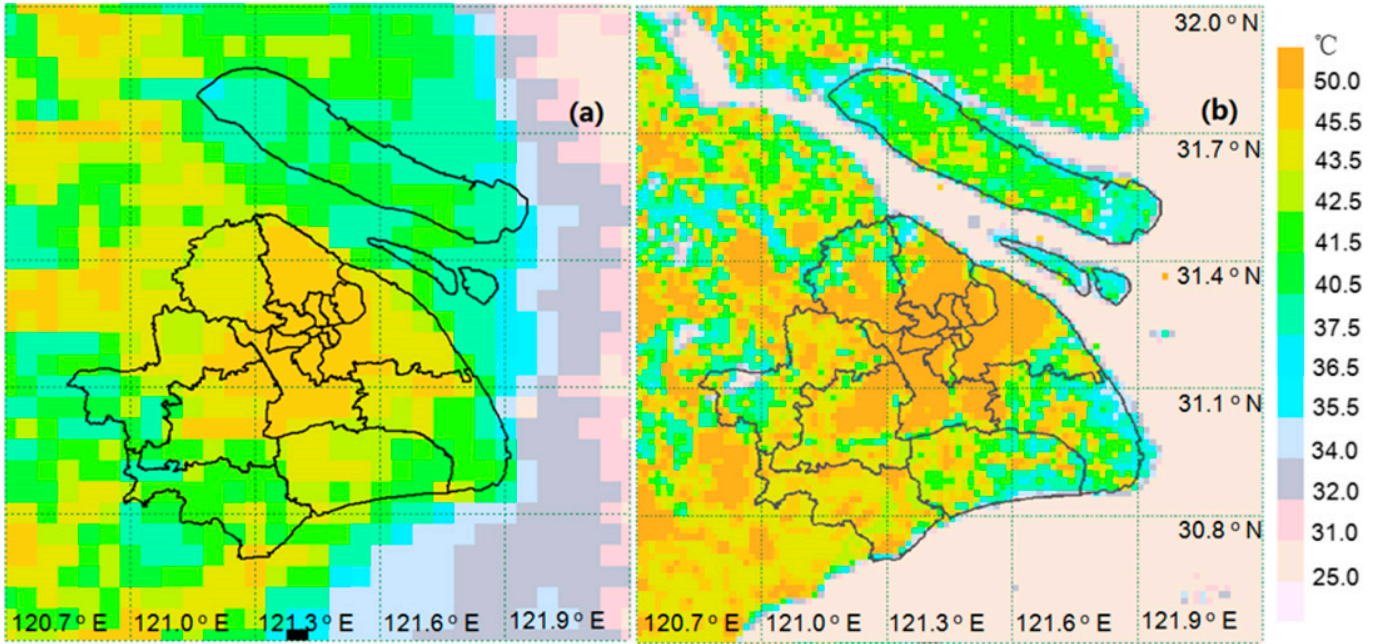

FIG. 6. Surface temperature $\left({ }^{\circ} \mathrm{C}\right.$ ) on 12 Aug 2013 derived from (a) MODIS (1040 LT) and (b) simulations (1100 LT).

Black lines delimit Shanghai and its districts.

the respective means. The forecast accuracy (FA) or hit rate is also used (Zhang et al. 2009):

$$
\mathrm{FA}_{T}=\frac{N_{G}}{N_{T}} \times 100 \%
$$

where $N_{T}$ is the total number of time steps evaluated, $N_{G}$ is the number of times that the forecast temperature has an absolute error $\leq 1^{\circ} \mathrm{C}$.

\section{Results and discussion}

\section{a. Surface temperatures}

The simulated hourly incoming shortwave flux and net all-wave radiation flux for clear days and cloudy days are compared with observations from the $\mathrm{XJH}$ tower (Fig. 4). Performance for both incoming shortwave and net all-wave radiation is better on clear days $\left(R^{2}=0.94\right.$ and 0.98$)$ than on cloudy days $\left(R^{2}=0.68\right.$ and 0.70$)$.

Violin plots allow both the distribution and frequency of the errors to be seen (Fig. 5). On clear days simulated incoming shortwave radiation is higher than observed in spring and summer, but lower in autumn and winter. On cloudy days generally, simulated incoming shortwave radiation is higher than the observed data for all seasons. The hourly incoming shortwave flux MAE are 35, 23, 34, and $24 \mathrm{~W} \mathrm{~m}^{-2}$ in spring, summer, autumn, and winter, respectively $\left(\mathrm{RMSE}=110,123,132\right.$, and $100 \mathrm{~W} \mathrm{~m}^{-2}$, respectively). The simulated transmissivity $T_{r}$ on clear days are $0.70,0.68,0.61$, and 0.66 on average in spring, summer, autumn, and winter, respectively, which follows the observed monthly median (1100-1300 LT) of 0.6-0.7 for clear conditions documented by Ao et al. (2016a).
On cloudy days, values are $0.65,0.58,0.53$, and 0.55 on average (spring, summer, autumn, and winter, respectively), which are higher than those derived from observations $(0.59,0.49,0.48$, and 0.47 , respectively) (Ao et al. 2016a).

Following Leroyer et al. (2011) and Zhang et al. (2011), modeled surface temperatures are compared to the MODIS skin temperature. The simulation values reproduce the general pattern well and give more detailed patterns of the surface urban heat island than is evident from MODIS (Fig. 6). The high temperature in the center of city does not have the surrounding gradient evident in

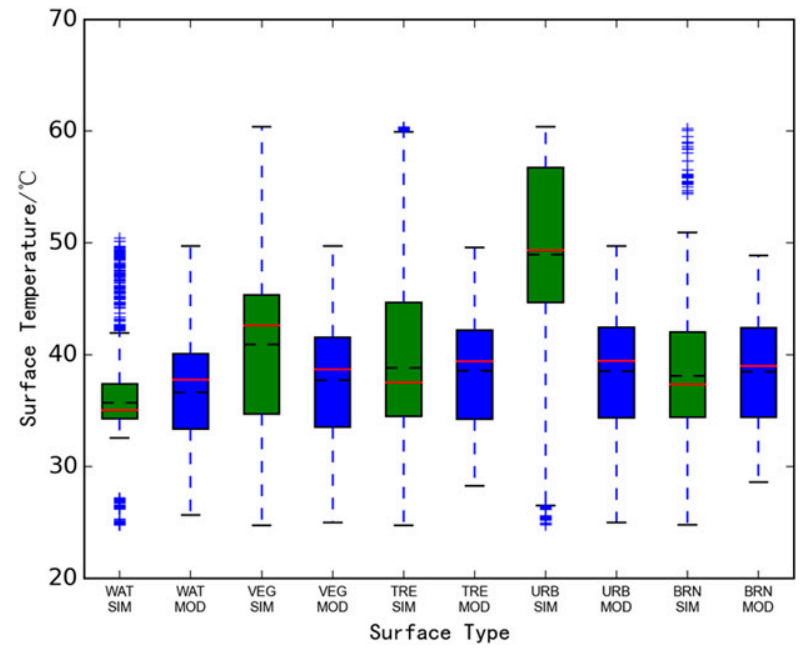

FIG. 7. Variation in surface temperature on four clear days in summer (1300 LT 3 Jun, 1300 LT 12 Jul, 1100 LT 11 Aug, and 1100 LT 12 Aug 2013) determined from MODIS (MOD) and simulation (SIM) by surface type (see Table 1 for classes in domain). Boxplots show interquartile range $(\mathrm{IQR}), 1.5 \times \mathrm{IQR}$ whiskers, median (red line), and mean (black dashed line). 


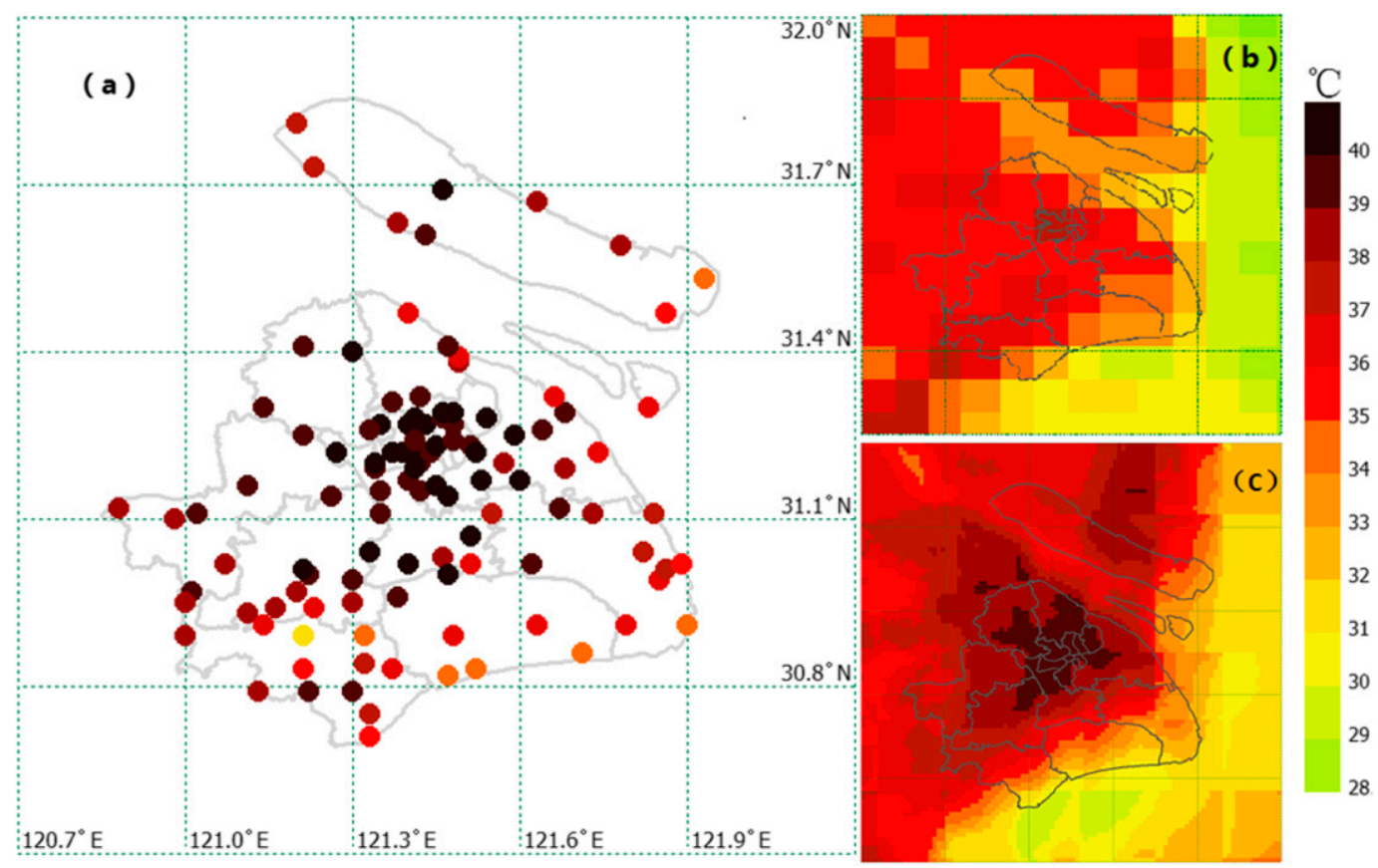

FIG. 8. Air temperature at $2 \mathrm{~m}$ above ground level in Shanghai at 1400 LT 27 Jul 2016 at (a) AWS observations, (b) ECMWF (1200 UTC) forecast, and (c) TsT2m [initialized with 1200 UTC (2000 LT) 26 Jul 2016 ECMWF forecast].

the MODIS skin temperature (Fig. 6a). Significantly lower temperatures near the Huangpu River in the city center are seen in the simulated temperatures (Fig. 6b). The Yangtze River and Chongming Island have similar temperature with the waters and land being hard to distinguish in Fig. 6a, but easy to distinguish in Fig. 6b. To evaluate the modeled results, the data are stratified by surface type (water, urban, short vegetation, trees and shrubs, and barren). The simulated surface temperature for urban areas $(N=16600)$ are $10.3^{\circ} \mathrm{C}$ warmer on average than those derived from MODIS, while the others are more similar [water: $-0.2^{\circ} \mathrm{C}(N=36936)$, short vegetation $3.1^{\circ} \mathrm{C}$ $(N=25411)$, trees and shrubs $0.1^{\circ} \mathrm{C}(N=12203)$, and barren ground $\left.-0.3^{\circ} \mathrm{C}(N=1158)\right]$. The larger difference associated with the urban surfaces is not unexpected as the coarser MODIS data are unlikely to only have the warmer built surfaces but will typically include cooler surface covers (e.g., grass, trees) as well.

Four cloud-free MODIS images are analyzed (1300 LT 3 June, 1300 LT 12 July, 1100 LT 11 August, and 1100 LT 12 August 2013) to investigate the performance of the surface temperature simulation for different land covers (Fig. 7). Observations of surface temperature are available at 10 national AWS sites. These are also used to evaluate the grids where they occur using the barren surface cover type. The barren surface temperatures' MBE and RMSE are $-2.8^{\circ}$ and $4.8^{\circ} \mathrm{C}$, while for the MODIS data they are $-5.2^{\circ}$ and $6.1^{\circ} \mathrm{C}$, respectively $(N=36)$.

\section{b. Near-surface air temperatures}

To evaluate the near-surface air temperature of Shanghai, a day with high temperatures is selected (27 July 2016). A mix of cloud and sun occurred, with low wind speeds from inland (southwest) and near the sea from the southeast. The downscaled air temperature distribution is compared to air temperatures from 110 AWS (Fig. 8) and the ECMWF high-resolution 2-m temperature prediction with 3-h temporal resolution and $0.125^{\circ}$ spatial resolution. The model is initialized at 2000 LT 26 July 2016 (i.e., the same time as the as ECMWF prediction) and temperatures simulated for $24 \mathrm{~h}$. At 1400 LT 27 July 2016, the highest air temperature areas are in the downtown area of Shanghai for all three approaches: the observations are the warmest $\left(\sim 41^{\circ} \mathrm{C}\right)$, TsT2 $\mathrm{m}$ is $39.8^{\circ} \mathrm{C}$, and ECMWF $\left(\sim 37^{\circ} \mathrm{C}\right)$ the coolest. Both ECMWF and TsT2m simulate lower temperatures near the sea, because of a sea breeze flowing in from the cooler sea surface. ECMWF has a secondary hot spot in the southwest corner of Shanghai, but this is not evident in the AWS or the TsT2m results.

For 1 May-31 October 2016, the near-surface air temperatures (Fig. 9) from ECMWF are mostly cooler than observed, except for some stations near the sea. In contrast, the TsT $2 \mathrm{~m}$ results are mostly warmer than observed, especially in the urban area. The RMSE $\mathrm{TsT2m}_{\mathrm{m}}$ are more spatially consistent than $\mathrm{RMSE}_{\mathrm{ECMWF}}$, as the latter are larger in the urban area than in the nonurban area. In August 

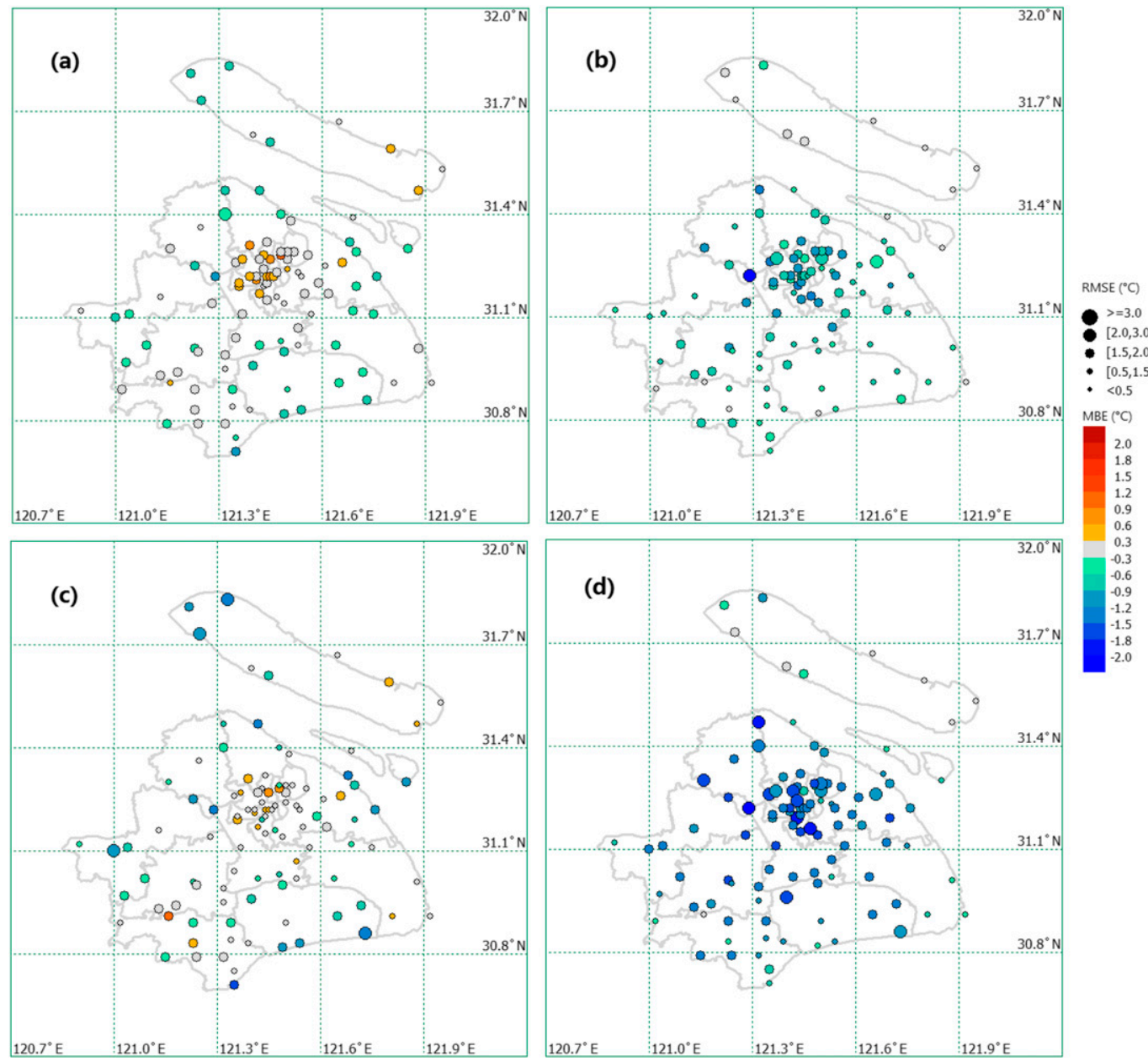

FIG. 9. Variation of MBE (color) and RMSE (dot size) for 2-m air temperature assessed with AWS data for (a),(b) May-October and (c),(d) August 2016 simulated by (a),(c) TsT2m and (b),(d) ECMWF.

(Figs. 9c,d), the hottest month in Shanghai, the $\mathrm{MBE}_{\mathrm{ECM}}$ is $<-1.0^{\circ} \mathrm{C}$ for 77 stations, and for 15 stations $\mathrm{RMSE}_{\mathrm{ECM}}$ is $>2.0^{\circ} \mathrm{C}$. Most of these are stations in the urban area. However, 96 stations have a $\mathrm{MAE}_{\mathrm{TsT2m}}<1.0^{\circ} \mathrm{C}$. The four stations with $\mathrm{RMSE}_{\mathrm{TsT} 2 \mathrm{~m}}>2.0^{\circ} \mathrm{C}$ are located close to the coast.

The average FA for the near-surface air temperature (Table 2) is better for $\mathrm{FA}_{\mathrm{TsT} 2 \mathrm{~m}}$ than $\mathrm{FA}_{\mathrm{ECM}}$ at almost all stations. In XJH and Chongming (CM) (Fig. 1), the full suite of TsT2m results are much better than those from the original ECMWF as both sites have a $20 \%$ higher FA. This also occurs in the MBE and RMSE (Fig. 10 shows XJH; others not shown). The $\mathrm{FA}_{\mathrm{TsT} 2 \mathrm{~m}}$ is better than $\mathrm{FA}_{\mathrm{ECM}}$ for every month, and much better in July (by $12.9 \%)$, August (24.8\%) and September (11.4\%). This indicates the TsT2m performance is much better on hot days $\left(\mathrm{MBE}_{\mathrm{TsT} 2 \mathrm{~m}}<1^{\circ} \mathrm{C}\right.$; $\mathrm{RMSE}_{\mathrm{TsT2m}}<3^{\circ} \mathrm{C}$ in each month) and better than the ECMWF forecast.
To evaluate the effect of the surface cover, the fractions of building and pavement (\%) for each station are determined (Fig. 11a, section 3a). FA $\mathrm{ECM}_{\mathrm{EC}}$ has a negative correlation with impervious cover (Fig. 11b) $\left(R^{2}=0.45\right.$, $t$-test significance $p=0.002$ for $\alpha=0.05)$. However, there is little influence of urban fractional cover on $\mathrm{FA}_{\mathrm{TsT2m}}$. Thus, the ECMWF prediction of temperature in urban areas (e.g., Xujiahui, Minghang, Songjiang) is modified from that of nonurban area (e.g., Fengxian, Qingpu, Pudong). The new TsT2m 2-m air temperature, by accounting for urban land cover, results in much improved performance for areas with road and built-up cover.

\section{c. Application}

A range of potential weather and climate service applications are possible with the new model. These include regular weather forecasts at higher spatial resolution and climate services mitigation applications. 
TABLE 2. Air temperature (at $2 \mathrm{~m}$ ) FA (\%) of ECMWF (ECM) and the TsT2m (T2m) at each station (Fig. 1) by month (May-October 2016).

\begin{tabular}{|c|c|c|c|c|c|c|c|c|c|c|c|c|}
\hline \multirow[b]{2}{*}{ Month } & $\mathrm{T} 2 \mathrm{~m}$ & ECM & $\mathrm{T} 2 \mathrm{~m}$ & ECM & $\mathrm{T} 2 \mathrm{~m}$ & ECM & $\mathrm{T} 2 \mathrm{~m}$ & ECM & $\mathrm{T} 2 \mathrm{~m}$ & $\mathrm{ECM}$ & $\mathrm{T} 2 \mathrm{~m}$ & ECM \\
\hline & \multicolumn{2}{|c|}{ BS } & \multicolumn{2}{|c|}{$\mathrm{CM}$} & \multicolumn{2}{|c|}{ FX } & \multicolumn{2}{|c|}{$\mathrm{JD}$} & \multicolumn{2}{|c|}{ JS } & \multicolumn{2}{|c|}{$\mathrm{MH}$} \\
\hline 5 & 55.0 & 38.3 & 61.1 & 46.1 & 63.6 & 61 & 54.7 & 39.2 & 55.5 & 56.6 & 54.1 & 46.4 \\
\hline 6 & 46.3 & 44.3 & 60.0 & 61.0 & 63.8 & 60.5 & 49.3 & 41.7 & 54.5 & 50.2 & 44.4 & 47.2 \\
\hline 7 & 53.7 & 37.0 & 70.7 & 52.4 & 65.8 & 61.5 & 51.7 & 33.1 & 49.7 & 53.3 & 46.1 & 34.3 \\
\hline 8 & 57.1 & 52.7 & 71.3 & 33.5 & 76.2 & 48.9 & 58.6 & 34.9 & 54.9 & 51.2 & 54.2 & 21.7 \\
\hline 9 & 57.5 & 62.3 & 60.1 & 38.0 & 60.6 & 60.8 & 57.5 & 57.7 & 66.7 & 50.4 & 55.9 & 35.5 \\
\hline 10 & 66.3 & 77.5 & 63.4 & 44.8 & 68.2 & 71.4 & 62.5 & 70.3 & 66.1 & 58.9 & 56.1 & 51.3 \\
\hline \multirow[t]{2}{*}{ Avg } & 56.0 & 52.0 & 64.4 & 46.0 & 66.4 & 60.7 & 55.7 & 46.2 & 57.9 & 53.4 & 51.8 & 39.4 \\
\hline & \multicolumn{2}{|c|}{ PD } & \multicolumn{2}{|c|}{$\mathrm{QP}$} & \multicolumn{2}{|c|}{ SJ } & \multicolumn{2}{|c|}{ XJH } & \multicolumn{2}{|c|}{ Avg } & & \\
\hline 5 & 53.7 & 48.0 & 56.9 & 53.2 & 49.7 & 50.6 & 50.8 & 38.2 & 55.5 & 47.8 & & \\
\hline 6 & 48.9 & 47.7 & 50.4 & 53.7 & 49.2 & 44.3 & 49.4 & 33.0 & 51.6 & 48.4 & & \\
\hline 7 & 46.9 & 44.3 & 61.7 & 47.9 & 56.3 & 36.7 & 53.0 & 26.4 & 55.6 & 42.7 & & \\
\hline 8 & 57.8 & 42.9 & 67.3 & 41.6 & 56.7 & 20.4 & 59.3 & 17.0 & 61.3 & 36.5 & & \\
\hline 9 & 57.0 & 49.9 & 61.5 & 61.5 & 55.4 & 38.5 & 64.0 & 27.5 & 59.6 & 48.2 & & \\
\hline 10 & 57.0 & 68.4 & 64.9 & 65.8 & 57.0 & 53.5 & 65.5 & 45.8 & 62.7 & 60.8 & & \\
\hline Avg & 53.6 & 50.2 & 60.5 & 54.0 & 54.1 & 40.7 & 57.0 & 31.3 & 57.7 & 54.4 & & \\
\hline
\end{tabular}

Here the impact of changing land cover for heat mitigation is assessed by analyzing the hottest day in Shanghai in 2016 using the same forcing data as in section 4b. The air temperature is simulated with the original land cover (section 3a) to characterize urban grids (i.e., paved areas $=58 \%$, buildings $=25 \%$, grass $=14 \%$, trees $=3 \%$ ). This is used as a reference temperature. Two more sets of simulations are conducted that have decreasing paved proportions $(58 \%-8 \%, 10 \%$ steps $)$ that are replaced with (i) grass or (ii) trees. The maximum and minimum daily air temperature for each urban grid $\left(T_{2 \mathrm{~m} \text {,max }}\right.$ and $T_{2 \mathrm{~m} \text {,min }}$, respectively) are compared (simulation minus reference temperature simulation) to obtain the change $\left(\Delta T_{2 \mathrm{~m} \text {,max }}\right.$ and $\Delta T_{2 \mathrm{~m}, \min }$, respectively) for each landcover change (Fig. 12).

The mean $T_{2 \mathrm{~m} \text {,max }}$ decreases with an increase in both grass and trees; therefore, $\Delta T_{2 \mathrm{~m} \text {,max }}$ becomes larger with an increase of grass or tree proportion. The reduction in $T_{2 \mathrm{~m} \text {,max }}$ is on average greater for an increase in trees $\left[0.45^{\circ} \mathrm{C}(10 \%)^{-1}\right]$ than grass $\left[0.37^{\circ} \mathrm{C}(10 \%)^{-1}\right]$. Similarly,

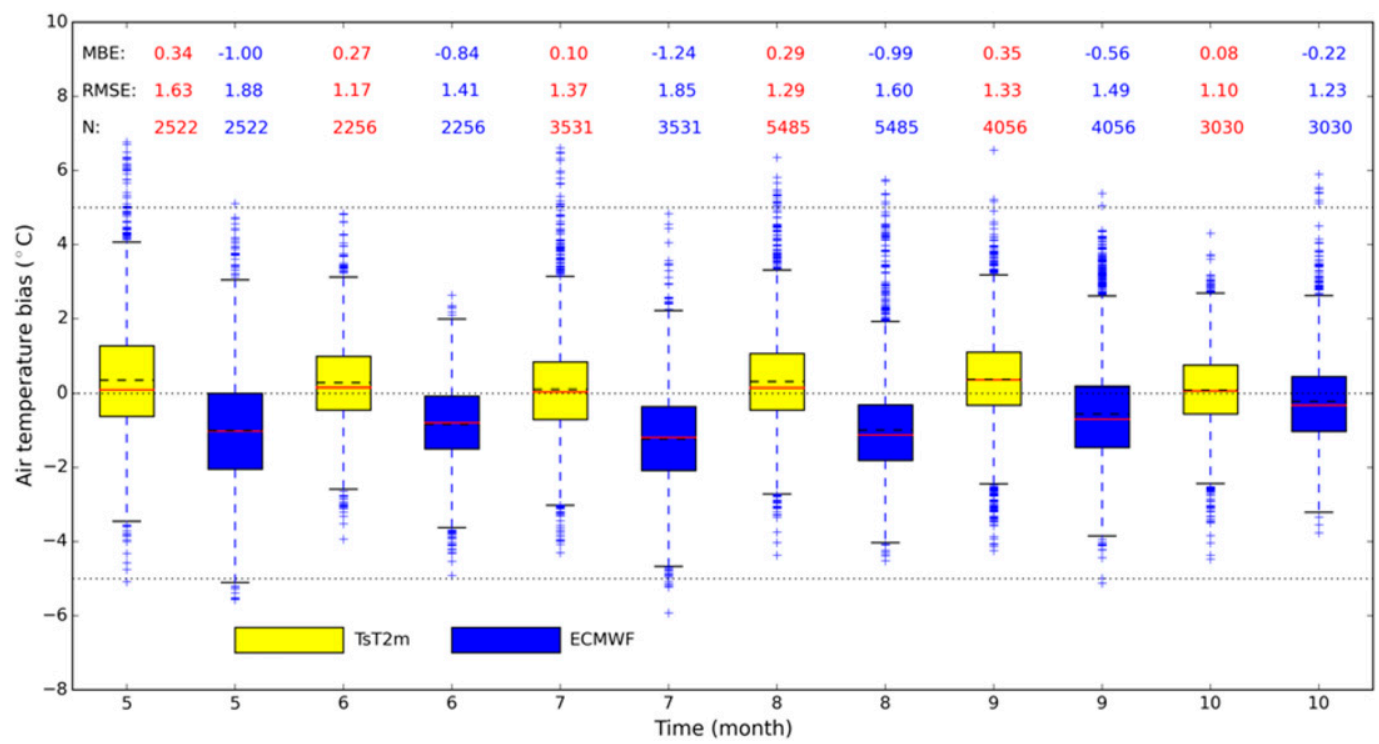

FIG. 10. Boxplot [IQR, median (red line), mean (black dotted line), whiskers $1.5 \times \mathrm{IQR}]$ of hourly air temperature bias at XJH using TsT2m and ECMWF from May (5) to October (10). 

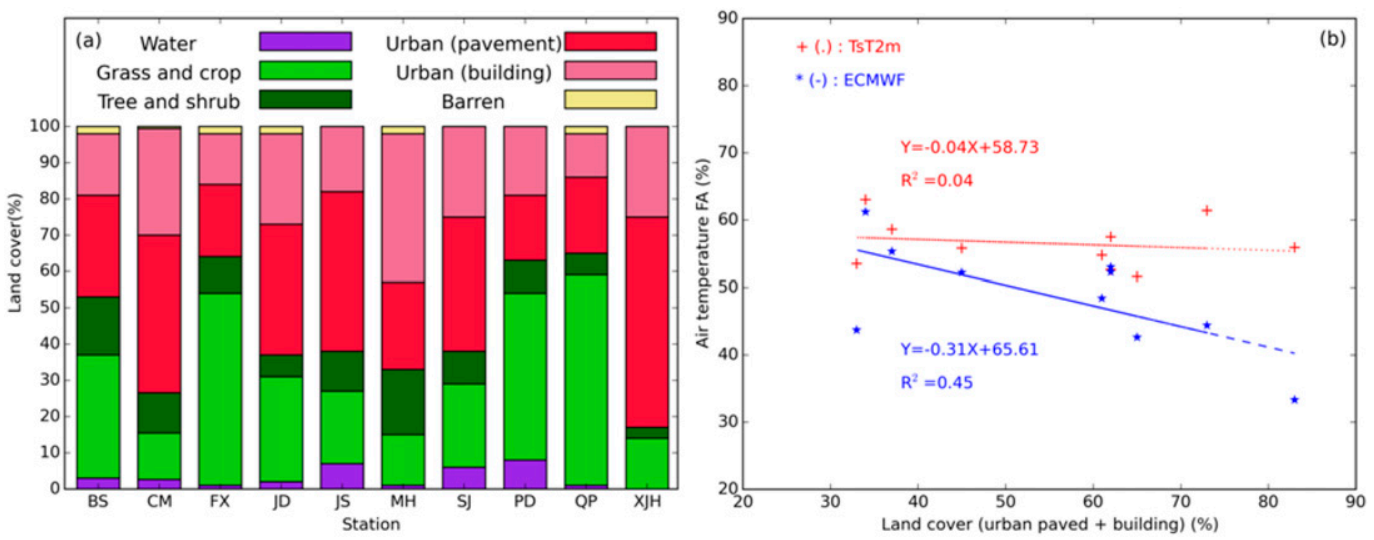

FIG. 11. Land-cover characteristics (a) within 1-km radius of the national stations (Fig. 1) and (b) urban percentage (paved + building) with FA of 2-m air temperature from May to October 2016.

the mean $T_{2 \mathrm{~m} \text {,min }}$ decreases with an increase in both grass and trees (Fig. 12b). The decrease associated with the trees $\left[0.063^{\circ} \mathrm{C}(10 \%)^{-1}\right]$ is larger than with grass $\left[0.026^{\circ} \mathrm{C}\right.$ $(10 \%)^{-1}$ ] but smaller than the impact on the maximum temperature (cf. Figs. 12a,b).

\section{Discussion and conclusions}

In this paper a new model (TsT2m) to downscale coarse NWP (e.g., ECMWF) forecast surface and air temperature based on underlying surface cover types is proposed. The approach provides higher temporal and spatial resolution outputs than traditional statistical downscaling. The model is assessed using AWS and MODIS data in Shanghai. For air temperature, the performance of the TsT2 $\mathrm{m}$ is better

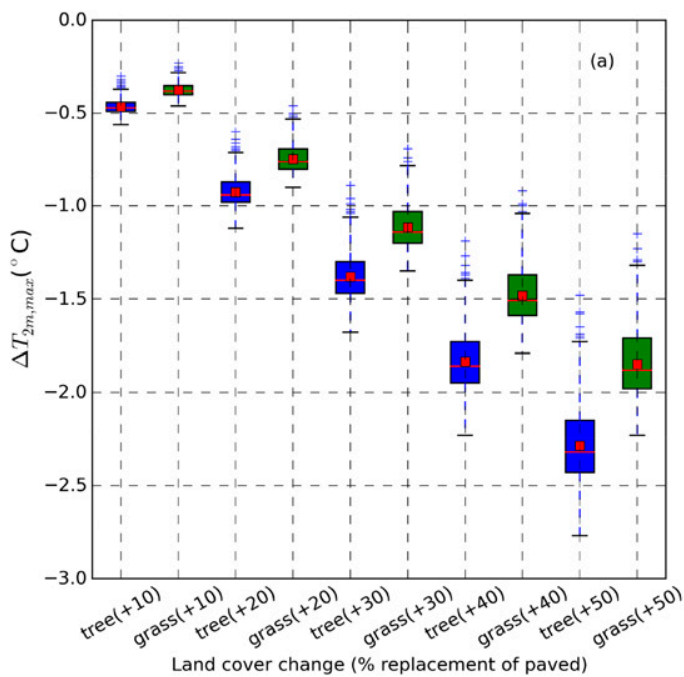

than the coarser (spatially and temporally) ECMWF forecast, and reflects better the impact of the environment on the near-surface $(2 \mathrm{~m})$ temperature. In Shanghai, enhanced performance is most evident on hot days. From May to October, the ECMWF 2-m air temperature forecast in the urban area is systematically cooler, while the mean and median errors of TsT2m are both smaller. As TsT2m mostly uses conventional meteorological data (temperature, humidity, wind speed, air pressure, cloud cover, etc.), and requires limited computing resources, it has great potential to be translated and extended to other cities and applications.

TsT2m performs less well in winter than summer. This may result from the assumption that air near ground is well mixed, which it less likely under more

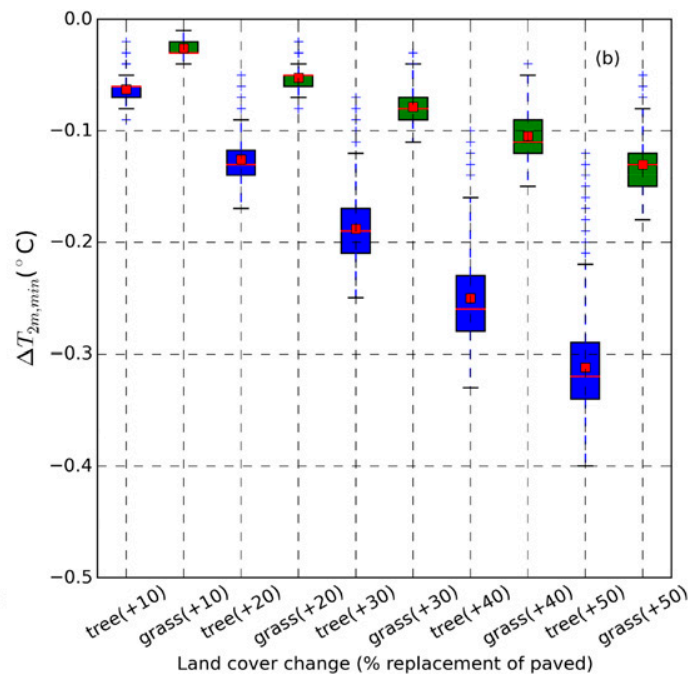

FIG. 12. Impact of change in surface cover [section 4c; pavement replaced by grass (green) or tree (blue)] on simulated (by TsT2m) daily air temperature (27 Jul 2016) (a) maximum $\left(\Delta T_{2 \mathrm{~m} \text {,max }}\right)$ and (b) minimum $\left(\Delta T_{2 \mathrm{~m}, \text { min }}\right)$. Spatial difference boxplot for all urban grids with IQR, and $1.5 \times$ IQR whiskers, median (red line), and mean (red diamond). Note $y$-scale differences. 
TABLE A1. List of symbols.

\begin{tabular}{|c|c|c|}
\hline Variable & Description & Units \\
\hline$A$ & Grid area & $\mathrm{m}^{2}$ \\
\hline$a_{1}$ & OHM coefficients & $-(0-1)$ \\
\hline$a_{2}$ & OHM coefficients & $-(0-1)$ \\
\hline$a_{3}$ & OHM coefficients & $\mathrm{W} \mathrm{m}^{-2}$ \\
\hline$C$ & Volumetric heat capacity of soil & $\mathrm{J} \mathrm{m}^{-3}{ }^{\circ} \mathrm{C}$ \\
\hline$C_{0}$ & Heat capacity per unit area & $\mathrm{J} \mathrm{m}^{-2 \circ} \mathrm{C}$ \\
\hline$c_{1}$ & Cloud transmittance without low cloud & $-(0-1)$ \\
\hline$c_{2}$ & Cloud transmittance without high cloud & $-(0-1)$ \\
\hline$C_{a}$ & Specific heat of air & $\mathrm{J} \mathrm{m}^{-3 \circ} \mathrm{C}$ \\
\hline $\mathrm{CC}_{1}$ & Total cloud-cover proportion & $-(0-1)$ \\
\hline $\mathrm{CC}_{2}$ & Lower/middle cloud-cover proportion & $-(0-1)$ \\
\hline$D$ & Day of year & Days \\
\hline$f_{\mathrm{e} \_\mathrm{s}}$ & Factor to account for deviation in mean Earth-sun distance & - \\
\hline$f_{i}$ & Proportion of a surface type & $-(0-1)$ \\
\hline$h$ & Sun zenith angle & $\mathrm{rad}$ \\
\hline$K_{\downarrow}$ & Incoming shortwave radiation & $\mathrm{W} \mathrm{m}^{-2}$ \\
\hline$K_{\uparrow}$ & Outgoing shortwave radiation & $\mathrm{W} \mathrm{m}^{-2}$ \\
\hline$K_{T}$ & Soil thermal conductivity & $\mathrm{W} \mathrm{m}^{-1}{ }^{\circ} \mathrm{C}^{-1}$ \\
\hline$L_{\downarrow}$ & Incoming longwave radiation & $\mathrm{W} \mathrm{m}^{-2}$ \\
\hline$L_{\uparrow}$ & Outgoing longwave radiation & $\mathrm{W} \mathrm{m}^{-2}$ \\
\hline$m$ & Optical mass & - \\
\hline$m_{a}$ & Mass of near-surface air block air quality & $\mathrm{kg}$ \\
\hline$p$ & Surface pressure & $\mathrm{hPa}$ \\
\hline$Q^{*}$ & Net all-wave radiation & $\mathrm{W} \mathrm{m}^{-2}$ \\
\hline$\widetilde{Q}_{E}$ & Latent heat flux & $\mathrm{W} \mathrm{m}^{-2}$ \\
\hline$Q_{F}$ & Anthropogenic heat flux & $\mathrm{W} \mathrm{m}^{-2}$ \\
\hline$Q^{F *}$ & Net all-wave radiation plus anthropogenic heat fluxes & $\mathrm{W} \mathrm{m}^{-2}$ \\
\hline$\widetilde{Q}_{H}$ & Sensible heat flux & $\mathrm{W} \mathrm{m}^{-2}$ \\
\hline$R_{0}$ & Solar constant & $\mathrm{W} \mathrm{m}^{-2}$ \\
\hline$T_{a}$ & Near-surface air temperature & ${ }^{\circ} \mathrm{C}$ \\
\hline$t_{a}$ & Absorption and scattering by aerosols & $-(0-1)$ \\
\hline$t_{c}$ & Cloud adjust coefficient & $-(0-1)$ \\
\hline$T_{d}$ & Deep soil temperature & ${ }^{\circ} \mathrm{C}$ \\
\hline$T_{\text {dew }}$ & Dewpoint & ${ }^{\circ} \mathrm{C}$ \\
\hline$t_{\mathrm{pg}}$ & Constant gas absorption & $-(0-1)$ \\
\hline$T_{r}$ & Atmospheric transmittance & $-(0-1)$ \\
\hline$t_{R}$ & Rayleigh scattering & $-(0-1)$ \\
\hline$T_{s}$ & Surface temperature & ${ }^{\circ} \mathrm{C}$ \\
\hline$T_{Z_{i}}$ & Air temperature at height of mixed air & ${ }^{\circ} \mathrm{C}$ \\
\hline$t_{w}$ & Water vapor absorption & $-(0-1)$ \\
\hline$Z_{i}$ & Height of well-mixed air block & $\mathrm{m}$ \\
\hline$\alpha$ & Surface albedo & $-(0-1)$ \\
\hline$\Delta Q_{a}$ & Internal energy change of the air block near surface & $\mathrm{W} \mathrm{m}^{-2}$ \\
\hline$\Delta \widetilde{L}_{\uparrow 0}$ & Surface longwave radiation change & $\mathrm{W} \mathrm{m}^{-2}$ \\
\hline$\Delta L_{\uparrow Z_{i}}$ & Longwave radiation change at the top of the air column & $\mathrm{W} \mathrm{m}^{-2}$ \\
\hline$\Delta Q_{a, h}$ & Net horizontal change in heat flux & $\mathrm{W} \mathrm{m}^{-2}$ \\
\hline$\Delta Q_{L_{-} v}$ & Net vertically change in heat flux & $\mathrm{W} \mathrm{m}^{-2}$ \\
\hline$\Delta Q_{S}$ & Storage heat flux & $\mathrm{W} \mathrm{m}^{-2}$ \\
\hline$\Delta t$ & Time step & $\mathrm{s}$ \\
\hline$\Delta T$ & Block air temperature change & ${ }^{\circ} \mathrm{C}$ \\
\hline$\mu$ & Precipitable water & $\mathrm{cm}$ \\
\hline$\varepsilon_{s}$ & Broadband surface emissivity & - \\
\hline$\varepsilon_{\text {sky }}$ & Broadband atmospheric emissivity & - \\
\hline$\rho$ & Air density & $\mathrm{kg} \mathrm{m}^{-3}$ \\
\hline
\end{tabular}


stable conditions. Currently, TsT2m does not consider hydrological processes. As surface moisture processes are important, their inclusion is important in future improvements. Heterogeneity of urban morphology influences land surface temperature (Guo et al. 2016) and this also will be considered in future studies. As TsT2m is tested only in Shanghai, evaluation in other cities is important to establish the robustness of the approach and its broader utility.

Given a lack of high-resolution observations to initialize the model, it is necessary to interpolate data, which inevitably introduces biases in the model simulations. Here, IDW is chosen given the local scale and as it yields continuous results. Obviously, inclusion of more AWSs in the interpolation will result in a better spatial representation.

The storage heat flux is sometimes overestimated with the OHM mode (especially in the afternoon). This may lead to an overestimate of $T_{s}$. Given the simplicity of OHM. and the fact it does not account for impacts of surface moisture and wind speed variations (Grimmond and Oke 1999), the first-order results of this study suggest that assessing the new analytical OHM (AnOHM) model (Sun et al. 2017) is warranted to increase OHM coefficients in future simulations.

$\mathrm{TsT} 2 \mathrm{~m}$ has the potential to be used to study finer-scale urban processes and conditions, for example: thermodynamic conditions of local convection, the effects of which are too small scale to be captured by a NWP models. Thus, TsT2m provides a useful tool for evaluating the impact of urbanization on the thermal environment and to inform city planning and design. TsT2m is developed with the aim of improving climate and weather services for heat stress conditions, particularly for those most vulnerable. The improved spatial resolution, particularly in the densest urban areas, will enable improved predictions and interventions and aid long-term planning for extreme heat conditions.

Acknowledgments. This work is supported by The National Natural Science Foundation of China Grants 41775019 (J.G. Tan) and 41475040 (M.B. Du) and the UK-China Research and Innovation Partnership Fund through the Met Office Climate Science for Service Partnership (CSSP) China as part of the Newton Fund (Grimmond, D.W. Liu, and J. Peng UK visit). Useful discussions with Ting Sun (Reading) are appreciated. There are no conflicts of interest.

\section{APPENDIX A}

\section{Symbols}

Symbols used in this paper are listed in Table A1.

\section{REFERENCES}

Allen, L., F. Lindberg, and C. S. B. Grimmond, 2011: Global to city scale urban anthropogenic heat flux: Model and variability. Int. J. Climatol., 31, 1990-2005, https://doi.org/10.1002/ joc. 2210 .

Anandakumar, K., 1999: A study on the partition of net radiation into heat fluxes on a dry asphalt surface. Atmos. Environ., 33, 3911-3918, https://doi.org/10.1016/S1352-2310(99)00133-8.

Ao, X., C. S. B. Grimmond, D. Liu, Z. Han, P. Hu, Y. Wang, X. Zhen, and J. Tan, 2016a: Radiation fluxes in a business district of Shanghai, China. J. Appl. Meteor.Climatol., 55, 2451-2468, https://doi.org/10.1175/JAMC-D-16-0082.1.

,-- , Y. Chang, D. Liu, Y. Tang, and P. Hu, 2016b: Heat, water and carbon exchanges in the tall megacity of Shanghai: Challenges and results. Int. J. Climatol., 36, 4608-4624, https:// doi.org/10.1002/joc.4657.

Arnfield, A. J., and C. S. B. Grimmond, 1998: An urban energy budget model and its application to urban storage heat flux modeling. Energy Build., 27, 61-68, https://doi.org/10.1016/ S0378-7788(97)00026-1.

Asaeda, T., and V. T. Ca, 1993: The subsurface transport of heat and moisture and its effect on the environment: A numerical model. Bound.-Layer Meteor., 65, 159-179, https://doi.org/ 10.1007/BF00708822.

Atwater, M. A., and P. S. Brown, 1974: Numerical computations of the latitudinal variation of solar radiation for an atmosphere of varying opacity. J. Appl. Meteor., 13, 289-297, https://doi.org/ 10.1175/1520-0450-13.2.289.

, and J. T. Ball, 1981: A surface solar radiation model for cloudy atmospheres. Mon. Wea. Rev., 109, 878-888, https://doi.org/ 10.1175/1520-0493(1981)109<0878:ASSRMF $>2.0 . C O ; 2$.

Basu, R., and J. M. Samet, 2002: Relation between elevated ambient temperature and mortality: A review of the epidemiologic evidence. Epidemiol. Rev., 24, 190-202, https://doi.org/ 10.1093/epirev/mxf007.

Bechtel, B., Z. Klemen, and H. Gholamali, 2012: Downscaling land surface temperature in an urban area: A case study for Hamburg, Germany. Remote Sens., 4, 3184-3200, https:// doi.org/10.3390/rs4103184.

Best, M. J., 1998: A model to predict surface temperatures. Bound.-Layer Meteor., 88, 279-306, https://doi.org/10.1023/ A:1001151927113.

- and C. S. B. Grimmond, 2015: Key conclusions of the First International Urban Land Surface Model Comparison Project. Bull. Amer. Meteor. Soc., 96, 805-819, https://doi.org/ 10.1175/BAMS-D-14-00122.1.

Bhumralkar, C. M., 1975: Numerical experiments on the computation of ground surface temperature in an atmospheric general circulation model. J. Appl. Meteor., 14, 1246-1258, https:// doi.org/10.1175/1520-0450(1975)014<1246:NEOTCO >2.0.CO;2.

Blackadar, A. K., 1976: Modeling the nocturnal boundary layer. Preprints, Third Symp. on Atmospheric Turbulence, Diffusion, and Air, Raleigh, NC, Amer. Meteor. Soc., 46-49.

Bonafoni, S., 2016: Downscaling of Landsat and MODIS land surface temperature over the heterogeneous urban area of Milan. IEEE J. Sel. Top. Appl. Earth Obs. Remote Sens., 9, 2019-2027, https://doi.org/10.1109/JSTARS.2016.2514367.

Chen, F., and J. Dudhia, 2001: Coupling an advanced land surfacehydrology model with the Penn State-NCAR MM5 modeling system. Part I: Model implementation and sensitivity. Mon. Wea. Rev., 129, 569-585, https://doi.org/10.1175/15200493(2001)129<0569:CAALSH>2.0.CO;2. 
Cohen, W. B., and Coauthors, 2006: MODIS land cover and LAI collection 4 product quality across nine states in the western hemisphere. IEEE Trans. Geosci. Remote Sens., 44, 1843-1857, https://doi.org/10.1109/TGRS.2006.876026.

Diefenderfer, B. K., I. L. Al-Qadi, and S. D. Diefenderfer, 2006: Model to predict pavement temperature profile: Development and validation. J. Transp. Eng., 132, 162-167, https://doi.org/ 10.1061/(ASCE)0733-947X(2006)132:2(162).

Doll, D., J. K. S. Ching, and J. Kaneshiro, 1985: Parameterization of subsurface heating for soil and concrete using net radiation data. Bound.-Layer Meteor., 32, 351-372, https://doi.org/ 10.1007/BF00122000.

Gabey, A. M., C. S. B. Grimmond, and I. Capel-Timms, 2018: Anthropogenic heat flux: Advisable spatial resolutions when input data are scarce. Theor. Appl. Climatol., https://doi.org/ 10.1007/s00704-018-2367-y, in press.

Gallo, P., A. L. McNab, T. R. Karl, J. F. Brown, J. J. Hood, and J. D. Tarpley, 1993: The use of NOAA AVHRR data for assessment of the urban heat island effect. J. Appl. Meteor., 32, 899-908, https://doi.org/10.1175/1520-0450(1993)032<0899: TUONAD $>2.0 . \mathrm{CO} ; 2$.

Grimm, N. B., S. H. Faeth, N. E. Golubiewski, C. L. Redman, J. G. Wu, X. M. Bai, and J. M. Briggs, 2008: Global change and the ecology of cities. Science, 319, 756-760, https://doi.org/10.1126/ science.1150195.

Grimmond, C. S. B., and T. R. Oke, 1999: Heat storage in urban areas: local-scale observations and evaluation of a simple model. J. Appl. Meteor., 38, 922-940, https://doi.org/10.1175/ 1520-0450(1999)038<0922:HSIUAL > 2.0.CO;2.

, H. A. Cleugh, and T. R. Oke, 1991: An objective urban heat storage model and its comparison with other schemes. Atmos. Environ., 25B, 311-326, https://doi.org/10.1016/0957-1272(91) 90003-W.

— ance Models Comparison Project: First results from phase 1. J. Appl. Meteor. Climatol., 49, 1268-1292, https://doi.org/ 10.1175/2010JAMC2354.1.

— , and Coauthors, 2011: Initial results from phase 2 of the International Urban Energy Balance Model Comparison. Int. J. Climatol., 31, 244-272, https://doi.org/10.1002/joc.2227.

Guo, G., X. Zhou, Z. Wu, R. Xiao, and Y. Chen, 2016: Characterizing the impact of urban morphology heterogeneity on land surface temperature in Guangzhou, China. Environ. Modell. Software, 84, 427-439, https://doi.org/10.1016/ j.envsoft.2016.06.021.

Herb, W. R., B. Janke, O. Mohseni, and H. G. Stefan, 2008: Ground surface temperature simulation for different land covers. J. Hydrol., 356, 327-343, https://doi.org/10.1016/ j.jhydrol.2008.04.020.

Honjo, T., H. Yamato, T. Mikami, and C. S. B. Grimmond, 2015: Network optimization for enhanced resilience of urban heat island measurements. Sustainable Cities Soc., 19, 319-330, https://doi.org/10.1016/j.scs.2015.02.004.

$\mathrm{Hu}, \mathrm{Z}$., and S. Islam, 1995: Prediction of ground surface temperature and soil moisture content by the force-restore method. Water Resour. Res., 31, 2531-2539, https://doi.org/10.1029/ 95WR01650.

Järvi, L., C. S. B. Grimmond, and M. Taka, 2014: Development of the Surface Urban Energy and Water Balance Scheme (SUEWS) for cold climate cities. Geosci. Model Dev., 7, 16911711, https://doi.org/10.5194/gmd-7-1691-2014.

Jin, M. S., W. Kessomkiat, and G. Pereira, 2011: Satellite-observed urbanization characters in Shanghai, China: Aerosols, urban heat island effect, and land-atmosphere interactions. Remote Sens., 3, 83-99, https://doi.org/10.3390/rs3010083.

Kalma, J. D., T. R. McVicar, and M. F. McCabe, 2008: Estimating land surface evaporation: A review of methods using remotely sensed surface temperature data. Surv. Geophys., 29, 421-469, https://doi.org/10.1007/s10712-008-9037-z.

Kim, Y. H., and J. J. Baik, 2005: Spatial and temporal structure of the urban heat island in Seoul. J. Appl. Meteor., 44, 591-605, https://doi.org/10.1175/JAM2226.1.

Leroyer, S., S. Belair, and J. Mailhot, 2011: Microscale numerical prediction over Montreal with the Canadian External Urban Modeling System. J. Appl. Meteor. Climatol, 50, 2410-2428, https://doi.org/10.1175/JAMC-D-11-013.1.

Li, R., Y. Zhang, and W. U. Jie, 2017: Interpolation methods for temperature distribution of urban communities in southern China (in Chinese). Build. Sci., 33 (12), 27-37.

Lindberg, F., and Coauthors, 2018: Urban Multi-scale Environmental Predictor (UMEP): An integrated tool for city-based climate services. Environ. Modell. Software, 99, 70-87, https:// doi.org/10.1016/j.envsoft.2017.09.020.

Loridan, T., C. S. B. Grimmond, B. D. Offerle, D. T. Young, T. E. Smith, L. Järvi, and F. Lindberg, 2011: Local-Scale Urban Meteorological Parameterization Scheme (LUMPS): Longwave radiation parameterization and seasonality-related developments. J. Appl. Meteor. Climatol., 50, 185-202, https:// doi.org/10.1175/2010JAMC2474.1.

Luo, Y., R. S. Loomis, and T. C. Hsiao, 1992: Simulation of soil temperature in crops. Agric. For. Meteor., 61, 23-38, https:// doi.org/10.1016/0168-1923(92)90023-W.

McCaughey, J. H., 1985: Energy balance storage terms in a mature mixed forest at Petawawa, Ontario-A case study. Bound.-Layer Meteor., 31, 89-101, https://doi.org/10.1007/BF00120036.

McDonald, J. E., 1960: Direct absorption of solar radiation by atmospheric water vapor. J. Meteor., 17, 319-328, https://doi.org/ 10.1175/1520-0469(1960)017<0319:DAOSRB > 2.0.CO;2.

Meyers, T. P., and R. F. Dale, 1983: Predicting daily insolation with hourly cloud height and coverage. J. Climate Appl. Meteor., 22 , 537-545, https://doi.org/10.1175/1520-0450(1983)022<0537: PDIWHC $>2.0 . \mathrm{CO} ; 2$.

Meyn, S. K., and T. R. Oke, 2009: Heat fluxes through roofs and their relevance to estimates of urban heat storage. Energy Build., 41, 745-752, https://doi.org/10.1016/j.enbuild.2009.02.005.

Mihailović, D. T., 1991: A model for prediction of the soil temperature and the soil moisture content in three layers. Z. Meteor., 41, 29-33.

_ 1996: Description of a land-air parameterization scheme (LAPS). Global Planet. Change, 13, 207-215, https://doi.org/ 10.1016/0921-8181(95)00048-8.

— environment. Ecol. Modell., 202, 465-475, https://doi.org/ 10.1016/j.ecolmodel.2006.11.009.

Molteni, F., R. Buizza, T. N. Palmer, and T. Petroliagis, 1996: The ECMWF Ensemble Prediction System: Methodology and validation. Quart. J. Roy. Meteor. Soc., 122, 73-119, https:// doi.org/10.1002/qj.49712252905.

Narita, K., T. Sekine, and T. Tokuoka, 1984: Thermal properties of urban surface materials: Study on heat balance at asphalt pavement. Geogr. Rev. Japan, 57, 639-651, https://doi.org/ 10.4157/grj1984a.57.9_639.

Nichol, J. E., W. Y. Fung, K. Lam, and M. S. Wong, 2009: Urban heat island diagnosis using ASTER satellite images and in situ air temperature. Atmos. Res., 94, 276-284, https://doi.org/ 10.1016/j.atmosres.2009.06.011. 
Novak, M. D., 1981: The moisture and thermal regimes of a bare soil in the Lower Fraser Valley during spring. Ph.D. thesis, University of British Columbia, Vancouver, BC, Canada, $153 \mathrm{pp}$.

Offerle, B., C. S. B. Grimmond, and T. R. Oke, 2003: Parameterization of net all-wave radiation for urban areas. J. Appl. Meteor., 42, 1157-1173, https://doi.org/10.1175/1520-0450(2003) 042<1157:PONARF $>2.0$. CO;2.

Oke, T. R., 1973: City size and the urban heat island. Atmos. Environ., 7, 769-779, https://doi.org/10.1016/0004-6981(73)90140-6.

_ 1988: The urban energy balance. Prog. Phys. Geogr., 12, 471508, https://doi.org/10.1177/030913338801200401.

_ 1995: The heat island of the urban boundary layer: Characteristics, causes and effects. Wind Climate in Cities, J. E. Cermak et al., Eds., NATO ASI Series E, Vol. 227, Kluwer Academic, 81-107.

O'Malley, C., P. A. E. Piroozfarb, E. R.P. Farr, and J. Gates, 2014: An investigation into minimizing urban heat island (UHI) effects: A UK perspective. Energy Procedia, 62, 72-80, https:// doi.org/10.1016/j.egypro.2014.12.368.

Pan, X., X. Li, X. Shi, X. Han, and L. Luo, 2012: Dynamic downscaling of near-surface air temperature at the basin scale using WRF-A case study in the Heihe River basin, China. Front. Earth Sci., 6 , 314-323, https://doi.org/10.1007/s11707-012-0306-2.

Raich, J. W., and W. H. Schlesinger, 1992: The global carbon dioxide flux in soil respiration and its relationship to vegetation and climate. Tellus, 44B, 81-99, https://doi.org/10.3402/tellusb.v44i2.15428.

Roberts, S. M., T. R. Oke, C. S. B. Grimmond, and J. A. Voogt, 2006: Comparison of four methods to estimate urban heat storage. J. Appl. Meteor. Climatol., 45, 1766-1781, https:// doi.org/10.1175/JAM2432.1.

Roth, M., T. R. Oke, and W. J. Emery, 1989: Satellite derived urban heat islands from three coastal cities and the utilization of such data in urban climatology. Int. J. Remote Sens., 10, 16991720, https://doi.org/10.1080/01431168908904002.

Shao, J., and P. J. Lister, 1996: An automated nowcasting model of road surface temperature and state for winter road maintenance. J. Appl. Meteor., 35, 1352-1361, https://doi.org/10.1175/ 1520-0450(1996)035<1352:AANMOR>2.0.CO;2.

Shepard, D., 1968: A two-dimensional interpolation function for regularly spaced data. Proc. 23rd National Conf. of American Computing Machinery, Princeton, NJ, Association for Computing Machinery, 517-524.

Smith, W. L., 1966: Note on the relationship between total precipitable water and surface dew point. J. Appl. Meteor. 5, 726-727, https://doi.org/10.1175/1520-0450(1966)005<0726: NOTRBT $>2.0 . \mathrm{CO} ; 2$.

South, C., C. S. B. Grimmond, and C. P. Wolfe, 1998: Evapotranspiration rates from wetlands with different disturbance histories: Indiana Dunes National Lakeshore. Wetlands, $\mathbf{1 8}$ 216-229, https://doi.org/10.1007/BF03161657.

Stone, J. B., and M. O. Rodgers, 2001: Urban form and thermal efficiency: How the design of cities influences the urban heat island effect. J. Amer. Plann. Assoc., 67, 186-198, https:// doi.org/10.1080/01944360108976228.

Sun, T., Z. H. Wang, W. Oechel, and C. S. B. Grimmond, 2017: The Analytical Objective Hysteresis Model (AnOHM v1. 0): Methodology to determine bulk storage heat flux coefficients. Geosci. Model Dev., 10, 2875-2890, https://doi.org/10.5194/ gmd-10-2875-2017.

Taesler, R., 1980a: Studies of the development and thermal structure of the urban boundary layer in Uppsala. Part I: Experimental program. Meteorological Institution, Uppsala University Rep. 61, 63 pp. , 1980b: Studies of the development and thermal structure of the urban boundary layer in Uppsala. Part II: Data analysis and results. Meteorological Institution, Uppsala University Rep. 61, 181 pp.

Taha, H., 1999: Modifying a mesoscale meteorological model to better incorporate urban heat storage: A bulk-parameterization approach. J. Appl. Meteor., 38, 466-473, https://doi.org/10.1175/ 1520-0450(1999)038<0466:MAMMMT>2.0.CO;2.

Tan, J., and Coauthors, 2015: Urban integrated meteorological observations: Practice and experience in Shanghai, China. Bull. Amer. Meteor. Soc., 96, 85-102, https://doi.org/10.1175/ BAMS-D-13-00216.1.

Taylor, K. E., 2001: Summarizing multiple aspects of model performance in a single diagram. J. Geophys. Res., 106, 71837192, https://doi.org/10.1029/2000JD900719.

Trumbore, S., O. A. Chadwick, and R. Amundson, 1996: Rapid exchange between soil carbon and atmospheric carbon dioxide driven by temperature change. Science, 272, 393-396, https://doi.org/10.1126/science.272.5260.393.

Van De Griend, A. A., and M. Owe, 1993: On the relationship between thermal emissivity and the normalized difference vegetation index for natural surfaces. Int. J. Remote Sens., 14, 1119-1131, https://doi.org/10.1080/01431169308904400.

Wang, X., Y. Li, K. Wang, X. Yang, and P. W. Chan, 2017: A simple daily cycle temperature boundary condition for ground surfaces in CFD predictions of urban wind flows. J. Appl. Meteor. Climatol., 56, 2963-2980, https://doi.org/ 10.1175/JAMC-D-17-0095.1.

Weng, Q., D. Lu, and J. Schubring, 2004: Estimation of land surface temperature-vegetation abundance relationship for urban heat island studies. Remote Sens. Environ., 89, 467-483, https://doi.org/10.1016/j.rse.2003.11.005.

Winkler, J. A., J. P. Palutikof, J. A. Andresen, and C. M. Goodess, 1997: The simulation of daily temperature time series from GCM output. Part II: Sensitivity analysis of an empirical transfer function methodology. J. Climate, 10, 2514-2532, https:/doi.org/ 10.1175/1520-0442(1997)010<2514:TSODTT>2.0.CO;2.

Xu, W., M. J. Wooster, and C. S. B. Grimmond, 2008: Modelling of urban sensible heat flux at multiple spatial scales: A demonstration using airborne hyperspectral imagery of Shanghai and a temperature-emissivity separation approach. Remote Sens. Environ., 112, 3493-3510, https://doi.org/10.1016/j.rse.2008.04.009.

Xue, Y., P. J. Sellers, J. L. Kinter, and J. Shukla, 1991: A simplified biosphere model for global climate studies. J. Climate, 4, 345-364, https://doi.org/10.1175/1520-0442(1991)004<0345: ASBMFG $>2.0 . \mathrm{CO} ; 2$.

Yoshida, A., K. Tominaga, and S. Watatani, 1990: Field measurements on energy balance of an urban canyon in the summer season. Energy Build., 15, 417-423, https://doi.org/10.1016/ 0378-7788(90)90016-C.

Yow, D. M., 2007: Urban heat islands: Observations, impacts, and adaptation. Geogr. Compass, 1, 1227-1251, https://doi.org/ 10.1111/j.1749-8198.2007.00063.x.

Zerenner, T., V. Venem, P. Friederichs, and C. Simmer, 2016: Downscaling near-surface atmospheric fields with multiobjective genetic programming. Environ. Modell. Software, 84, 85-98, https://doi.org/10.1016/j.envsoft.2016.06.009.

Zhang, D. L., Y. X. Shou, R. R. Dickerson, and F. Chen, 2011: Impact of upstream urbanization on the urban heat island effects along the Washington-Baltimore corridor. J. Appl. Meteor. Climatol., 50, 2012-2029, https://doi.org/10.1175/JAMC-D-10-05008.1.

Zhang, Q., A. Y. Xiong, J. Y. Zhang, M. N. Feng, and B. M. Wang, 2009: Preliminary study on the scoring methods of cloud-free rainfall/snowfall and air temperature forecasts (in Chinese). J. Appl. Meteor. Sci., 20, 692-698. 